\title{
Planetary Geologic Mapping-Program Status and Future Needs
}

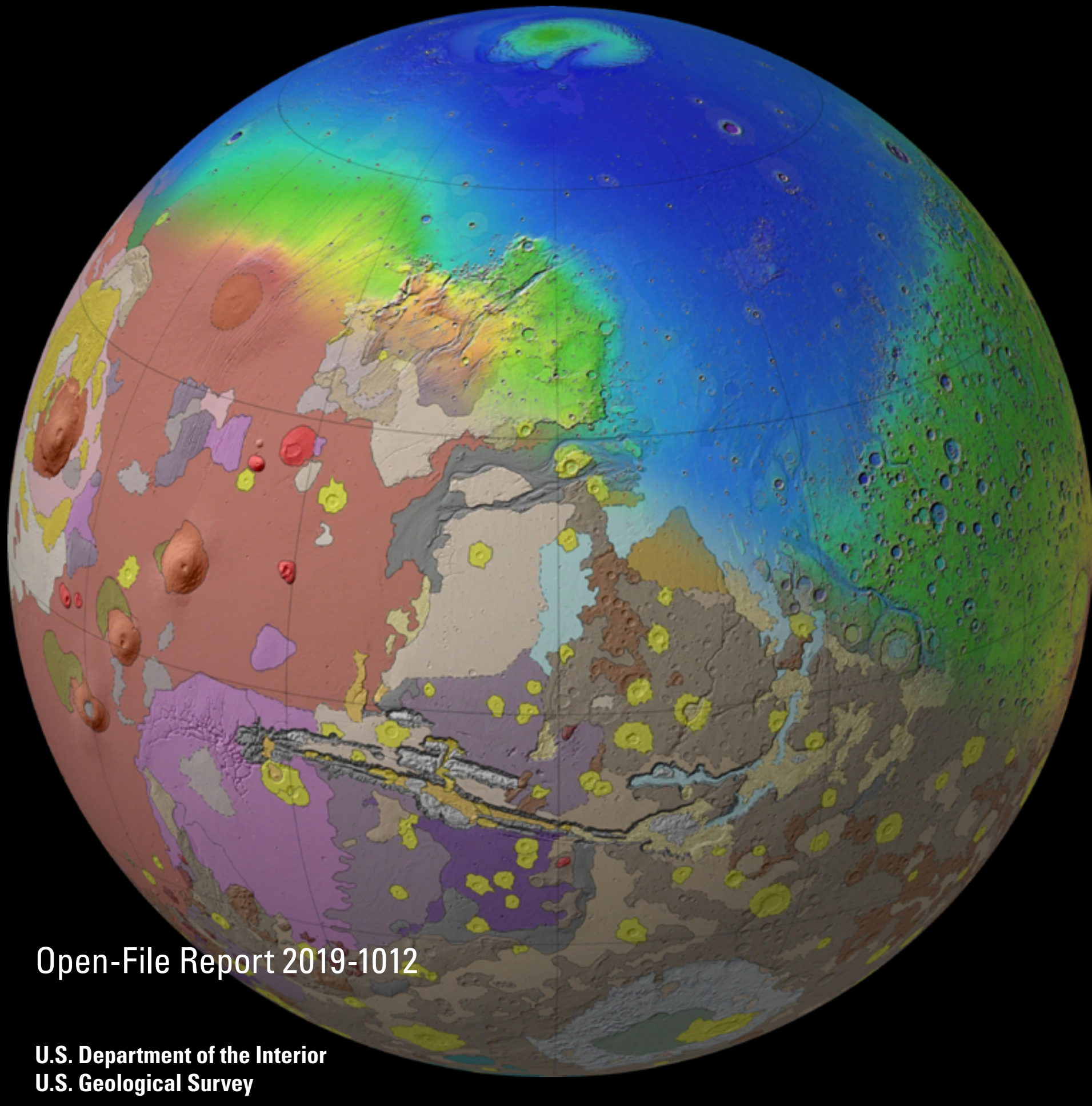


Cover. The global-scale geologic units of Mars, as shown by draping USGS SIM 3292 (Tanaka and others, 2014) over a Mars Orbiter Laser Altimeter (MOLA) color-shaded relief map in orthographic projection. 


\section{Planetary Geologic Mapping-Program Status and Future Needs}

By James A. Skinner, Jr., Alexandra E. Huff, Corey M. Fortezzo, Tenielle Gaither,

Trent M. Hare, Marc A. Hunter, and Holly Buban

Open-File Report 2019-1012 


\title{
U.S. Department of the Interior \\ DAVID BERNHARDT, Acting Secretary
}

\author{
U.S. Geological Survey \\ James F. Reilly II, Director
}

U.S. Geological Survey, Reston, Virginia: 2019

For more information on the USGS - the Federal source for science about the Earth, its natural and living resources, natural hazards, and the environment-visit https://www.usgs.gov or call 1-888-ASK-USGS (1-888-275-8747).

For an overview of USGS information products, including maps, imagery, and publications, visit https://store.usgs.gov.

Any use of trade, firm, or product names is for descriptive purposes only and does not imply endorsement by the U.S. Government.

Although this information product, for the most part, is in the public domain, it also may contain copyrighted materials as noted in the text. Permission to reproduce copyrighted items must be secured from the copyright owner.

Suggested citation:

Skinner, J.A. Jr., Huff, A.E., Fortezzo, C.M., Gaither, T., Hare, T.M., Hunter, M.A., Buban, H., 2019, Planetary geologic mapping — program status and future needs: U.S. Geological Survey Open-File Report 2019-1012, 40 p.,

https://doi.org/10.3133/ofr20191012

ISSN 2331-1258 (online) 


\title{
USGS Astrogeology Science Center-Planetary Geologic Map Coordination Group
}

\author{
James A. Skinner, Jr. \\ Alexandra E. Huff \\ Corey M. Fortezzo \\ Tenielle A. Gaither \\ Trent M. Hare \\ Marc A. Hunter \\ Holly C. Buban \\ with review input from \\ Mike Bland, (USGS Astrogeology) \\ Devon Burr, (University of Tennessee) \\ Colin Dundas, (USGS Astrogeology) \\ Lisa Gaddis, (USGS Astrogeology) \\ Laz Kestay, (USGS Astrogeology) \\ Jay Laura, (USGS Astrogeology) \\ Pete Mouginis-Mark, (University of Hawaii Manoa) \\ Sharon Purdy-Wilson, (Smithsonian Institution) \\ Chris Okubo, (USGS Astrogeology) \\ Dave Williams, (Arizona State University)
}




\section{Contents}

USGS Astrogeology Science Center-Planetary Geologic Map Coordination Group ......................iii

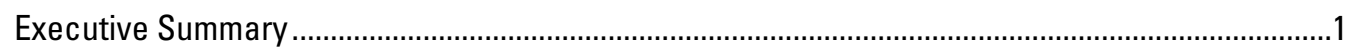

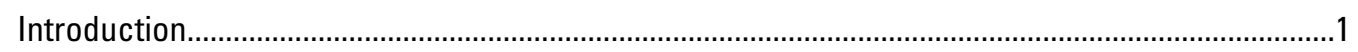

USGS-NASA Planetary Geologic Mapping Program ..................................................................

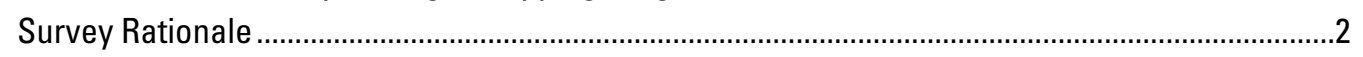

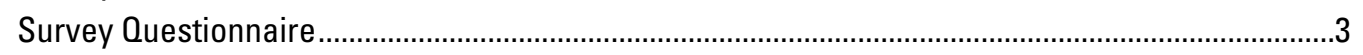

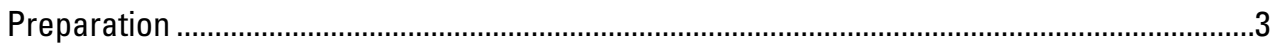

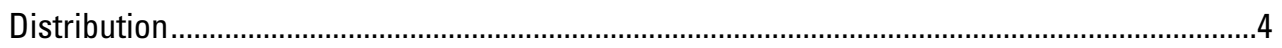

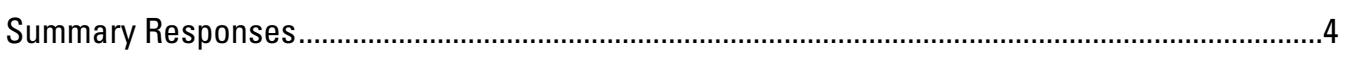

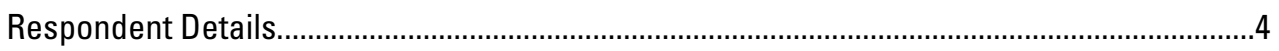

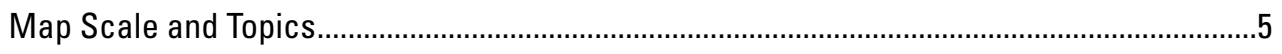

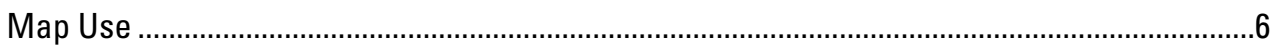

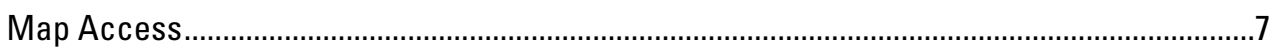

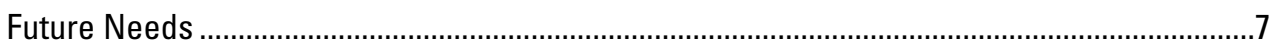

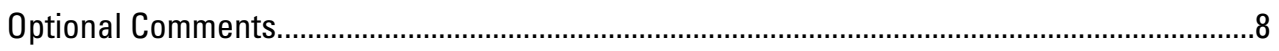

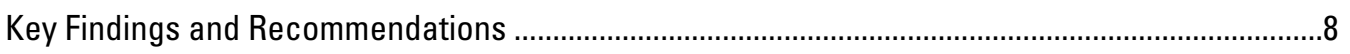

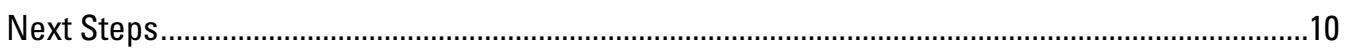

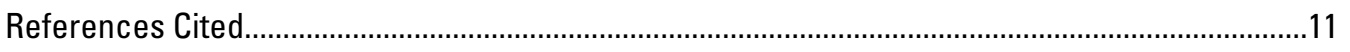

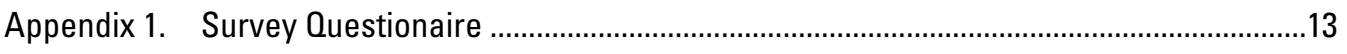

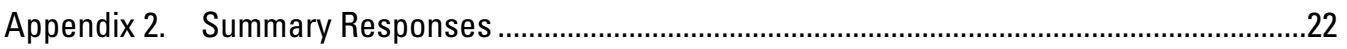

\section{Appendix Figures}

1.1. Cover and instructions to survey questionnaire.........................................................13

1.2. Questions 1 through 3 on the topic of respondent career and organizational

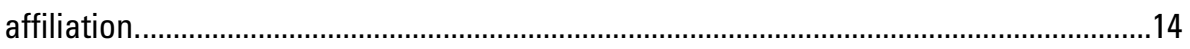

1.3. Questions 4 through 6 on the nature of respondent work and funding ........................14

1.4. Questions 7 and 8 on the topic of relevant planetary bodies or systems and data types..

1.5. Question 9 through 12 on the topics of software services and respondent role in use or creation of geoscience maps...

1.6. Questions 13 and 14 on why respondents do not use geoscience maps, prompted by a "never" response to Question 12 (frequency of geoscience map use)................16

1.7. Questions 15 and 16 on the topics of map scale and geoscience map types used .....17

1.8. Question 17 on the relevance of geologic process to respondent work .......................18

1.9. Questions 18 through 20 on the importance of map publication source, elements, and the use of non-standardized maps that contain standard symbol sets and formats.

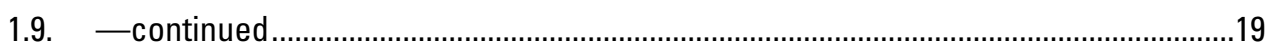

1.10. Question 21 on the use of geoscience maps to establish context and question 22 on respondent knowledge of map standard mapping methods. 
1.11. Questions 23 through 24 on respondent access to geoscience maps, importance of maps to respondent work and the importance of a single, online geoscience map repository.

1.12. Questions 26 through 29 on topics concerning the future needs of the geoscience map community.

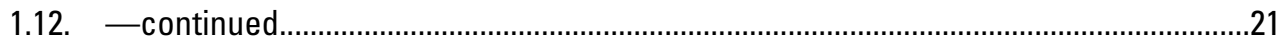

1.13. Question 30 providing respondents the ability to comment regarding planetary

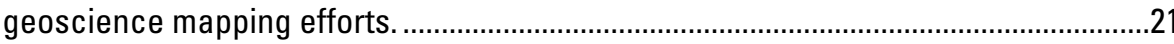

2.1. Responses showing a majority of respondent work based in university, college, or

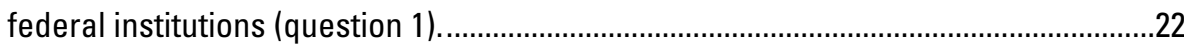

2.2. Responses indicating stages of career in which respondents reside (question 2).....22

2.3. Respondents area of discipline as chosen through a selection of up to three choices

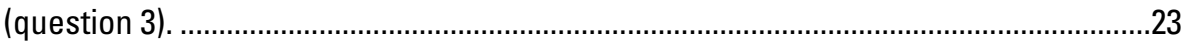

2.4. Respondents type of work as selected through three options (question 4)................24

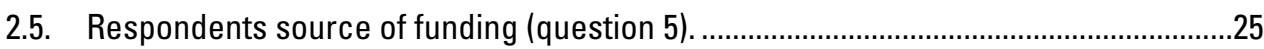

2.6. Respondent involvement in active mission planning, operations, or affiliated

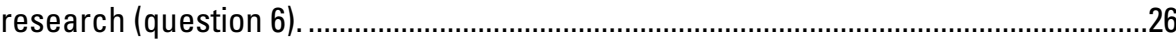

2.7. Relevance of planetary bodies or systems to respondent work (question 7)...............27

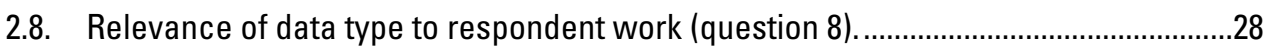

2.9. Importance of software and services to respondent work (question 9).......................29

2.10. Presence of hard-copy USGS-published planetary geologic map in respondent

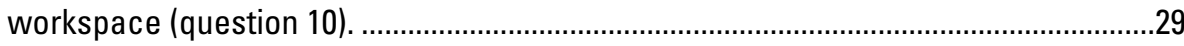

2.11. Frequency of geoscience map creation by respondents (question 11) .......................30

2.12. Frequency of geoscience map use by respondents (question 12) ..............................30

2.13. Respondent response and reason for lack of geoscience map use (question 13) ......31

2.14. Relevance of map scale to respondent work (question 15)...........................................

2.15. Relevance of geoscience map type to respondent work (question 16).......................32

2.16. Relevance of unit, terrain and (or) feature type to respondent work (question 17).....33

2.17. Importance of geoscience map publication type to respondent work (question 18)..34

2.18. Importance of map elements to respondent work (question 19).................................35

2.20. Relevance of geoscience maps to respondents in establishing context for scientific

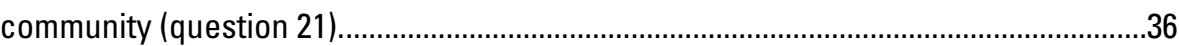

2.19. Respondent evaluation of standard cartographic symbols in non-standardized geoscience maps (question 20).....................................................................................

2.21. Evaluation of respondent confidence in applying standard mapping processes

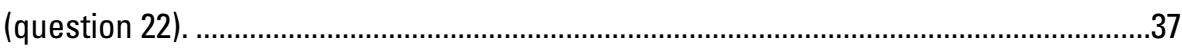

2.22. Respondent evaluation of geoscience map accessibility (question 23)......................37

2.24. Respondent preference towards a single online repository of geoscience maps

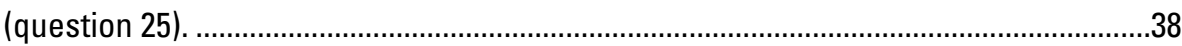

2.23. Importance of map formats to respondent work (question 24). .................................38

2.26. Respondent evaluation of expedited production of standardized geoscience maps (question 27).

2.27. Respondent evaluation of multi-year mapping campaigns for particular planetary bodies and map scales (question 28).

2.25. Respondent evaluation of geoscience maps as fundamental to surface science investigations (question 26).

2.28. Likelihood of respondent use of topical mapping guidance (question 29). 


\section{Tables}

1. Email listserv and social media details for releasing the survey questionnaire. The survey was posted to listserv and social media groups on March 27, 2017.

2. Units, terrains, and (or) features per body that respondents indicated were "very relevant" in proportions greater than "somewhat relevant" or "not relevant". Determined by cross-comparing question 7 (body relevance) with question 17 (unit/terrain/feature relevance). 


\title{
Planetary Geologic Mapping-Program Status and Future Needs
}

\author{
By James A. Skinner, Jr., Alexandra E. Huff, Corey M. Fortezzo, Tenielle Gaither, Trent M. Hare, Marc A. \\ Hunter, and Holly Buban on behalf of the USGS-NASA Planetary Geologic Mapping Program
}

\section{Executive Summary}

The United States Geological Survey's (USGS) Planetary Geologic Map Coordination Group (Flagstaff, Ariz.) surveyed planetary geoscience map makers and users to determine the importance, relevance, and usability of such products to their planetary science research and to current and future needs of the planetary science community. This survey was prepared because the planetary science community lacks a modern assessment of the value invested in geoscience map products and processes (including the diverse scientific and technical personnel who add to and maintain this infrastructure) and a strategy that ensures these efforts appropriately prioritize mapping efforts across all solid surface bodies in the Solar System. A 30-question survey was conducted through an online questionnaire and was designed to (1) take $<10$ minutes, (2) instill a sense that responses would be acted upon, and (3) encourage community participation through a user-friendly interface. There was no intention to identify and then require responses from named members within the planetary science community nor was there an attempt to target a specific set of discipline scientists. As a result, we understand and fully acknowledge that the cumulative responses represent a "self-selected" set of perceptions about planetary geoscience maps.

The survey made a distinction between "standardized" geoscience maps (those published by the USGS that require adherence to specific cartographic standards, conventions, and principles) and "non-standardized" geoscience maps (those published by other venues such as peer-reviewed journals that are not required to, but might, adhere to some cartographic standards, conventions, and principles). The survey was opened on Sunday, March 18, 2017 (to coincide with the annual Lunar and Planetary Science Conference in The Woodlands, Tex.) and was closed on Thursday, May 25, 2017. There was a total of 265 unique responses.

Responses were formulated into 17 unique findings that are matched with one or more recommendations to be addressed by the planetary science community. In general, both standardized and non-standardized planetary geoscience maps are broadly valued as a community resource and both appear to fill a critical role in research and exploration. Standard approaches to planetary geoscience mapping, regardless of publication venue, are deemed important and efforts should be made within the community to not only continue support for these products but also to capture and transfer the knowledge associated with map-making to sustain the endeavor in the long-term through university classes and training of post-graduate students. Global to hemispheric-scale standardized geologic maps should be made for all solid surface bodies within the Solar System for which they do not already exist (and for which adequate data are available). For those bodies or planetary systems that already have such maps, efforts should focus, at least in part, on campaigning at set scales (or a narrow range of scales) and for particular types of terrains. Geomorphological, surficial, and compositional maps are deemed legitimate and useful geoscience maps and efforts should be made to adapt existing approaches to accommodate their creation as standardized products. Control to standard reference frame, objectivity of unit description, and use of standard symbol sets are highly valued in geoscience maps and increased efforts should be made to assist a larger part of the community in meeting these standards in the geoscience map-making process. The community is strongly encouraged to discuss minimum cartographic standards for all geoscience map products, both standardized and non-standardized. Once established, the community should provide open database schemas, symbol sets, tools, and tutorials needed to enable the broadest part of the community to make maps that meet those minimum standards. Digital maps, especially GIS format maps, are the most valued, though there appears to be difficulty in the community on finding and using the maps, particularly in digital format. As such, the community is encouraged to explore the technical, managerial, and financial means by which all planetary geoscience maps, regardless of publication venue, could be searched for and accessed in a single location.

\section{Introduction}

Geoscience maps, regardless of target body, are spatial and temporal representations of materials and processes recorded on planetary surfaces (Varnes, 1973; Spencer, 2000). The information and context provided by these maps promote basic and applied research within and across various geoscience disciplines. They also provide an important basis for programmatic and policy decisions (for example, H.R. $2763-102^{\text {nd }}$ Congress, National Geologic Mapping Act of 1992). Since 1961, planetary geoscience maps (maps that summarize the geology of all solid surface bodies in the Solar System beyond Earth) have been used in nearly every facet of planetary exploration, from landing site characterization for human (for example, Grolier, 1970) and robotic (for example, 
Anderson and Bell, 2010) missions to mineralogical analyses of water-alteration on Mars (for example, Loizeau and others, 2007). Modern planetary geoscience maps are either standardized (those published by the United States Geological Survey (USGS) that require adherence to cartographic standards, conventions, and principles) or non-standardized (those published by other organizations that are not required to, but might, adhere to some cartographic standards, conventions, and principles). Geoscience mapping and its resultant map product, whether standardized or non-standardized, is widely considered a routine reconnaissance and contextual investigation that should be performed in advance of and (or) in tandem with surface science investigations. Geoscience mapping campaigns are systematically included in mission proposals as anticipated derivative products (for example, Williams and others, 2014), along with other high-order cartographic data products such as controlled-image mosaics and digital terrain models. Additionally, planning documents from multiple planetary-science focused programs, organizations, and institutions identify geoscience maps as key scientific and technical results from and contributors to planetary exploration strategies (Planetary Decadal Survey, 2011; MEPAG, 2015; Hendrix and others, 2018). In line with these community uses and priorities, the National Aeronautics and Space Administration (NASA), in cooperation with the USGS Astrogeology Science Center (Flagstaff, Ariz.), has built and maintained a significant infrastructure dedicated not only to producing geoscience maps but also to building and releasing mappingbased resources to the planetary science community.

\section{USGS-NASA Planetary Geologic Mapping Program}

The USGS-NASA Planetary Geologic Mapping Program is a multi-decades-long cooperative program between the USGS and NASA whose objective is to define the geology of all solid surface bodies (other than Earth) in the Solar System by making, distributing, and supporting the use of geoscience maps. This Program is managed by the USGS Planetary Geologic Map Coordination Group (hereafter USGS Planetary Mapping Group) that is tasked with building, supporting, and maintaining planetary geoscience maps as reliable scientific context for conducting research and supporting a long-lived, robust planetary exploration strategy. In ongoing efforts to fulfill this task, the USGS Planetary Mapping Group works to generate, distribute, and maintain policies and resources for the construction and use of planetary geoscience maps, both standardized and non-standardized, by the planetary science community. We note that NASA planetary geoscience maps supported and eventually published by the USGS Planetary Mapping Group are based on the explicit direction of NASA program officers.

The USGS is effectively the default publication venue for NASA-funded research projects that generate a standardized product because of its long history with establishing and using mapping standards. These projects are currently published as USGS Scientific Investigation Maps (SIM) series products. As such, the USGS Planetary Mapping Group not only develops the requirements involved in making standardized products (with community input) but also manages the progression, production, and formal standards review of NASA-funded maps to ensure a baseline level of objectivity and adherence to cartographic standards, conventions, and principles through peer review. Most of the resources provided by the USGS Planetary Mapping Group are directly related to the generation of SIM series maps that meet USGS mapping standards. The USGS publishes formal map products that result from NASAfunded projects that have been through such a review.

The Program has significant interest in the production of all planetary geoscience maps and provides varying levels of assistance to all researchers who produce planetary geoscience maps, regardless of publication venue, institutional affiliation, or nationality. All resources (for example, mapping-based process documents, tutorials, guidelines, and standards) are intended to be used to produce geoscience maps, standardized or non-standardized, and there are certainly other publication venues under which planetary geoscience maps have been - and should continue to be-published, including peerreviewed journal articles. Even though planetary geoscience maps are recognized as important products that both document and drive exploration of worlds beyond Earth, currently there is no other institution, organization, or program that provides an equivalent service to the national and international community. However, the planetary science community lacks a modern assessment of the value of NASA's significant investment in geoscience map products and processes (including the diverse scientific and technical personnel who add to and maintain this infrastructure) and a strategy that ensures these efforts appropriately balance and prioritize mapping efforts across all solid surface bodies in the Solar System.

\section{Survey Rationale}

As part of its charge to maintain and advocate for the construction and use of reliable planetary geoscience map products, and to assess the scientific value placed by the community in geoscience map products and processes, the USGS Planetary Mapping Group compiled and released a survey of planetary geoscience map makers and users (summarized in the "Distribution" section below). The survey was intended to assess the importance, relevance, and usability of planetary geoscience maps within the science community. More explicitly, survey responses were designed to help determine current and future needs related to production and use of geoscience maps for multiple bodies within the Solar System and to ensure that geoscience maps adequately meet the scientific and technical needs of the broadest part of the planetary science community possible in the short- and long-term. This survey, the summary responses, and recommendations provided herein 
are intended to contribute to a larger, more focused effort to recognize and promote data processes and products as key to a successful planetary exploration strategy by improving the community's recognition that raw data alone is insufficient to satisfy short- and long-term exploration goals.

The recommendations herein address four audiences: (1) the strategic and programmatic decision makers (NASA and international administrators of space exploration), (2) scientific and technical coordinators and facilitators (USGS Planetary Mapping Group, community advisory and working groups), (3) planetary geoscience map makers (planetary geoscience mappers), and (4) planetary geoscience map users (planetary science community, engineers, program managers, policy-makers, and the public). However, specific audiences are not identified per recommendation to avoid limiting community-wide improvement and to encourage multiple audiences to contribute to and benefit from any recommendation herein. Recommendations are purposefully non-thematic to allow for innovative responses and action by various audiences. Further discussions and interpretations of the survey results, as well as the range of interpretations and resultant recommendations, are strongly encouraged.

\section{Survey Questionnaire}

\section{Preparation}

The survey questionnaire was designed to capture input from respondents who represent the broadest part of the planetary science community that have a self-described interest in the production and (or) use of planetary geoscience maps. The questionnaire leveraged the approaches taken by past surveys and questionnaires that assessed similar use and need statistics for terrestrial geologic maps. To obtain a high level of response, the questionnaire was designed to (1) take $<10$ minutes, (2) instill a sense that responses would be acted upon, and (3) encourage participation through easy interfacing. The survey questionnaire was developed through multiple rounds of input and review. External review came from community members, including the Mapping and Planetary Spatial Data Infrastructure Team (MAPSIT) steering committee, and discipline scientists who complete geoscience mapping as part of their work, as well as those who do not.

Gathering input from the general planetary science community presents a challenge by making it difficult to ensure that all survey respondents, regardless of scientific discipline, understand the definition and use cases of mapping-specific terms included within the survey questionnaire. To mitigate possible misunderstandings, a section of the front page of the survey defined the following terms:

- Geoscience maps-Maps that discretely delineate and describe units or terrains using base maps (for example, geologic, structural, geomorphological, stratigraphic maps).
- Base maps-Derived data products upon which units or terrains may be identified (for example, controlled mosaics, digital terrain models, elemental composition).

- Standardized maps - Geoscience maps published by USGS that require adherence to cartographic standards, conventions, and principles.

- Non-standardized maps - Geoscience maps published by other venues (for example, peer review journal, thesis/ dissertation, special issue, book chapter) that are not required to, but might, adhere to some cartographic standards, conventions, and principles.

- When not specified, assume that 'geoscience maps' indicate both standard and non-standardized products.

This document applies the same definition and use cases as summarized above. 'Geoscience maps' is pointedly used in this document because, though 'geologic' is used in the Program and Group name, the USGS Planetary Mapping Group acknowledges that geologic maps are a subset or group of map types under the umbrella of all geoscience maps relevant to planetary science investigations.

The questionnaire was organized into five sections with a total of 30 questions: (1) a "Respondent Details" section consisting of 12 questions, (2) a "Map Scales and Topics" section consisting of 3 questions, (3) a "Map Use" section consisting of 5 questions, (4) a "Map Access" section consisting of 3 questions, and (5) a "Future Needs" section consisting of 4 questions. Only the 12 questions in the first section in the survey questionnaire were required. The "Respondent Details" section asked for non-sensitive, wholly anonymous details about each respondents' self-identified educational/research background and work efforts, specifically type of organization, career stage, scientific and (or) technical discipline, funding source, mission involvement, bodies of interest, relevant data sets, software services used, and the frequency with which maps are made and used. No questions inquired about respondent's personally identifiable information, race, ethnicity, gender, age, or sexual orientation. The "Map Scales and Topics" section asked respondents for information regarding the range of relative map scales and topics as well as terrain types, processes, and environments that are relevant to their work, irrespective of the target body of interest. The "Map Use" section asked for information about how respondents use geoscience maps, what geoscience map elements respondents deem important, and how the respondents perceive the role of geoscience maps in establishing context on various planetary bodies. The "Map Access" section asked for information about how respondents locate and access geoscience maps and what formats they perceive as most important. The "Future Needs" was designed to ascertain how respondents perceive geoscience maps can and (or) should be used to establish and refine scientific context, how mapping processes can be improved upon, and how geoscience maps can and (or) should support exploration goals, including surface science conducted by current and future landed assets. In addition to these five sections, 
the questionnaire allowed respondents to post optional comments to expand on any topic deemed relevant. To preserve anonymity, these responses are not included herein but are described and categorized in a subsequent section. The questionnaire, as distributed, is provided in appendix 1. Responses per question are provided in appendix 2. Cross-correlated questions, as discussed in the following sections, are provided purely as reference information in appendix 3 through appendix 7 to support the statistics reported herein (Skinner and others, 2018).

\section{Distribution}

The finalized survey questionnaire contained 30 questions displayed over 8 web pages (appendix 1). The questionnaire was prepared using SurveyMonkey, Inc., an online survey development company that specializes in cloud-based survey services. This mode of release was selected because it allowed users to access the survey anonymously using a variety of web-enabled devices. The survey questionnaire was opened on Sunday March 19, 2017, to coincide with the Lunar and Planetary Science Conference (LPSC), which convenes annually in The Woodlands, Tex. The survey was responded to 26 times during the week of the LPSC (10\% of total responses). The survey was then posted to various listserv and social media groups on March 27, 2017. It was responded to 199 times $(75 \%$ of total) during the following three days, with the remaining 40 responses $(15 \%)$ submitted within the subsequent two weeks. The survey was closed on Thursday May 25,2017 . The questionnaire was advertised to community members via a weblink and QR code printed on business cards (distributed at LPSC), as a link in an email to community listservs, and through social media platforms (table 1).

There was neither an intent to identify and then require responses from a statistically selected set of members within the planetary science community, nor was there an attempt to target a specific set of discipline scientists. As a result, it is understood and fully acknowledged that the cumulative responses represent a "self-selected" set of perceptions about planetary geoscience maps by only those people who wanted to respond. It cannot be assumed that responses can be applied to the entirety of the planetary science community. However, reasonable judgements can be made about the importance of planetary geoscience maps based on survey responses generally and respondents who self-identify as frequent or occasional map users specifically. This survey was intended to capture a range of information about planetary map use and future needs where there was previously no such information.

\section{Summary Responses}

A total of 265 responses to the questionnaire were received. The following is a summary of responses per section as well as results from selected cross-correlated questions. Readers are encouraged to review the detailed responses to the survey questionnaire (appendix 2) as well as results of crosscorrelating selected questions (appendix 3 through appendix 7). Cross-correlations are indicated with the symbol " $\times$ ". For example, "Q7 × Q17" means Question 7 cross-correlated with Question 17. We identify notable "findings" as first-order implications from question responses and cross-correlations. In subsequent sections, these findings are matched with one or more "recommendations" that can be addressed by the planetary science community.

\section{Respondent Details}

The first section of the questionnaire requested details about the anonymous respondents and was completed by all 265 respondents (in short, no survey-taker quit the questionnaire prior to finishing this section). This section was designed to accumulate specific details about respondent background (for example, organization, career stage, funding source) as a point of correlation and cross-comparison to later questions.

Responses to question 1 indicate that university/college and federal institutions constitute by far the largest organizational groups (75\%) whereas the second largest category was non-teaching, non-governmental research institutions $(20 \%)$. The stages of career in which respondents reside are diverse (question 2) but focus on early, middle, or late career

Table 1. Email listserv and social media details for releasing the survey questionnaire. The survey was posted to listserv and social media groups on March 27, 2017.

\begin{tabular}{ccc}
\hline Group & Platform & $\begin{array}{c}\text { Members/Subscribers } \\
\text { (at time of posting) }\end{array}$ \\
\hline Planetary Geologic Mapping Community & Listserv & 118 \\
NextGen Lunar Scientists and Engineers & Listserv & 146 \\
Lunar-L & Listserv & 690 \\
Mercury-planet & Listserv & 105 \\
Young Scientists for Planetary Exploration & Facebook & 1,795 \\
NextGen Lunar Scientists and Engineers & Facebook & 120 \\
\hline
\end{tabular}


professionals (69\%). Scientific discipline per respondent was assessed in question 3 using a "select up to three" question that included 11 potential choices (including "other") that have varying use for geoscience maps. This question was designed to acknowledge that many scientists self-affiliate with both a primary discipline and sub-discipline. There were 488 total selections to this question, implying that most respondents self-identify with at least two scientific disciplines. Respondents predominately identify geology/geomorphology as their primary discipline (71\%), with geophysics, GIS, and geochemistry/cosmochemistry/petrology as secondary disciplines. The type of work conducted by respondents was assessed through a "select up to three" question (question 4), wherein the overwhelming work type was "research" (93\%), followed by "image processing/archiving/dissemination" (24\%) and "education (university of college)" (21\%). The "other" category was selected by $<5$ percent of respondents. There were 541 total selections to this question, implying that not only do most respondents self-identify with at least two types of work but that respondents often perceive their research to be critically coupled with educational (university or college) or technical expertise (image processing/archiving/planning, mission planning, or instrument/payload concept development). NASA is the dominant funding source (72\%) for respondent work activities (question 5) and 56 percent of respondents are specifically involved in missions (planning, operations, and (or) research) (question 6). Mars, the Moon, and Earth are the most relevant planetary bodies/systems for respondent work (question 7), with broad consistency for Mercury, asteroids, and outer planet satellite systems at lower levels, based on "very relevant" responses. The relevance of data type to respondent work efforts was assessed in question 8, with the following data types identified as "very relevant": "topography/DTM" (81\%), "orthoimages and image mosaics" (78\%), and "controlled image mosaics" (70\%). Every data type category (except "other") garnered $>80$ percent "very relevant" or "somewhat relevant" cumulative response, implying that respondents favor certain data sets but clearly find value in the full range of data. Similarly, respondents find GIS and image processing software/services the most relevant (question 9), but they value a broader range of services including Planetary Data System (PDS) and web-map services. A majority of respondents $(75 \%)$ have a hardcopy USGS map in their office or workspace (question 10). Respondents often use geoscience maps (62 percent of respondents to question 11) but were less likely to have made geoscience maps as by-products or final products of their work (35 percent of respondents to question 12). However, of the 35 percent of respondents who answered "often" when queried about creating geoscience maps in their work effort (question 11), 94 percent answered "often" when queried about using geoscience maps in their work effort (question 12). Of the 23 percent of respondents who answered "never" when queried about creating geoscience maps in their work effort (question11), 25 percent answered "often" and 60 percent answered "occasionally" when queried about using geoscience maps in their work effort (question 12).
FINDING 1: Planetary geoscience maps are used more frequently by map makers, though respondents who never make maps still use them as a resource for their work and value them as critical contextual products.

Three percent of total respondents reported never using geoscience maps in question 12 and were provided an exit page to the survey questionnaire (question 13). Therein, respondents stated that limiting factors for geoscience map use included maps are generally inapplicable to their line of work, lack of existing maps relevant to their research background, poor access, lack of objectivity, and incompatible formats. No respondent, when given an exit page to the survey, used the opportunity to provide additional comments (question 14).

\section{Map Scale and Topics}

The second section of the survey requested information regarding geoscience map scales and topics as well as the types of terrains that are relevant to respondents' work efforts. Respondents indicated in this section that all map scales - from local to global - are very relevant to their work. However, cross-correlating question 7 (body relevance) and question 15 (map scale relevance) (appendix 3), indicates that respondents prefer local to regional scales only when hemispheric to global scales already exist. For example, respondents who identify outer planet systems as "very important" also identify "hemispheric and global scales" as the most relevant whereas respondents who identify the Martian system as "very important" identify "local to regional scales" as the most relevant. We interpret these responses as indicating that local to regional scale geoscience maps become more relevant only after geologic and stratigraphic context has been established at hemispheric and global scales. These responses may imply that effective and long-lived geoscience mapping efforts are those that establish geologic and stratigraphic context at smaller scales (larger areas) before progressing to larger scales (smaller areas) rather than vice versa or at an arbitrary or selfselected variety of scales. Alternatively, or perhaps in addition to the above implication, respondents who study outer planets and icy satellites recognize that, in general, there is insufficient data for many of those bodies to support local to regional mapping. As such, respondents understand that global products are the only viable option.

FINDING 2: Local to regional scale maps are valued more highly when hemispheric to global scale geoscience maps have already identified broadly occurring units and established their spatial and temporal context.

Every map type (except hydrogeologic maps and "other") garnered $>75$ percent very relevant and somewhat relevant cumulative responses, with geologic maps, geomorphologic maps, surficial geology maps, and compositional maps having 90 percent "very relevant" and "somewhat relevant" cumulative response (question 16). Geologic maps had the highest 


\section{Planetary Geologic Mapping_Program Status and Future Needs}

"very relevant" response at 68 percent. There were slight differences in the relevance of map types based on the planetary body or system that respondents deemed "very relevant" to their work (question $16 \times$ question 7) (appendix 4), particularly regarding an increased relevance of compositional maps for asteroids, Mercury, and the Moon.

FINDING 3: Geologic maps are perceived as the most relevant planetary geoscience map type, though geomorphologic, surficial, and compositional maps are also relevant map types.

The relevance of different unit, terrain, and (or) feature types were assessed in question 17. Respondents identified volcanic, impact-related, stratified, ancient crustal, and fluvial/alluvial as very relevant to their work. The relevance of these units, terrains, and (or) features is consistent, even when cross-correlated with body relevance (question $17 \times$ question 7) (appendix 5). With few exceptions, volcanic and impact-related terrains were deemed the most relevant for all solid surface bodies in the Solar System, though there were other units, terrains, and features that were deemed relevant depending on the body (table 2).

FINDING 4: Volcanic and impact-related units, features, and terrains are the most widely relevant for solid surface bodies throughout the Solar System, though there are other units, features, and terrains that are perceived as relevant on bodies that have more diverse geologic histories.

\section{Map Use}

The third section of the survey requested information about how respondents use maps, what elements or characteristics they deem important, and how they perceive the role of geoscience maps in establishing context for the exploration of planetary bodies. Respondents indicated that both USGSpublished and peer-reviewed journal maps are more important to their work than maps presented in theses, dissertations, and book chapters (question 18). When queried about the importance of various map elements to their work (question 19), respondents indicated that maps that are controlled to a standard coordinate system, have objectivity in unit descriptions, and apply consistent use of symbols were "very important" whereas comparability in map scale and in look and feel were "somewhat important".

FINDING 5: Control to standard reference frame, objectivity in unit description, and consistent use of symbols are the three most important elements of planetary geoscience maps.

Question 20 asked respondents whether non-standardized geoscience maps (that is, those not published by the USGS) that implement standard cartographic symbol sets and formats are "more useful", "equally useful", or "less useful" than those that do not. Respondents indicated that non-USGS published planetary geoscience maps that implement standardized cartographic symbols and formats are more useful or equally useful than those that do not in equivalent proportions $(43 \%)$. Only 14 percent of respondents indicated that the implementation of standard symbols and formats makes a non-standardized map less useful. Respondents overwhelmingly indicated that standardized maps are very important to establishing context for the scientific community compared to non-standardized maps (question 21).

FINDING 6: Standardized and non-standardized geoscience maps are equally valued, though maps that follow cartographic standards are more effective at establishing context for the scientific community.

Table 2. Units, terrains, and (or) features per body that respondents indicated were "very relevant" in proportions greater than "somewhat relevant" or "not relevant". Determined by cross-comparing question 7 (body relevance) with question 17 (unit/terrain/ feature relevance).

\begin{tabular}{ll}
\hline \multicolumn{1}{c}{ Body } & \multicolumn{1}{c}{ Units, terrains, features (\% very relevant) } \\
\hline $\begin{array}{l}\text { Mercury } \\
\text { Venus }\end{array}$ & Impact-related (74), Volcanic (68) \\
Moon & Volcanic (76), Impact-related (49) \\
Volcanic (71), Impact-related (69), Ancient-crustal (41) \\
$\begin{array}{l}\text { Mars (including Deimos and } \\
\text { Phobos) }\end{array}$ & $\begin{array}{l}\text { Volcanic (62), Impact-related (54), Fluvial/Alluvial (50), Stratified (47), Ancient-Crustal (43), } \\
\text { Aqueously-altered (42), Aeolian (39) }\end{array}$ \\
$\begin{array}{l}\text { Main belt asteroids } \\
\text { Jovian system }\end{array}$ & $\begin{array}{l}\text { Impact-related (65), volcanic (54) } \\
\text { Saturnian system }\end{array}$ \\
$\begin{array}{l}\text { Impact-related (68), Volcanic (52), Mass-wasting (44), Ancient-crustal (41), Fluvial/Alluvial (38) } \\
\text { Uranian/Neptunian system }\end{array}$ & Impact-related (69), Densely-faulted (43), Mass-wasting (43), Ancient Crustal (38), Fluvial/Allu- \\
Pluto (including Charon) & Impact-related (57), Mass-wasting (45), Stratified (35), Glacial/Periglacial (30) \\
\hline
\end{tabular}


Question 22 asked respondents whether they agree or disagree, along a continuum of 5 choices, that they are knowledgeable of and can confidently apply standard geologic mapping process. Respondents indicated that they "strongly agree" $(28 \%)$ or "somewhat agree" (37\%). "Somewhat disagree" and "strongly disagree" garnered 17 percent of cumulative responses. Those respondents who frequently make and use geoscience maps self-report as more knowledgeable and confident appliers of standard mapping processes compared to those who infrequently make and use such products (question $11 \times$ question 22 and question $12 \times$ question 22) (appendix $6)$.

FINDING 7: Frequent geoscience map users and (or) makers are more knowledgeable of standard geologic mapping processes, though there appears to be a lack of strong community knowledge related to application of standard geologic mapping processes.

\section{Map Access}

The fourth section of the questionnaire requested information about how respondents locate and access geoscience maps and queried what map formats and resources they deem most important. Respondents indicated that standardized (USGS-published) planetary geoscience maps are generally easier to locate, access, and use than non-standardized (peerreviewed journal maps) (question 23). The high proportion of moderate to negative responses regarding the ease of locating, accessing, and using both standardized and non-standardized maps is notable.

FINDING 8: Even though standardized geoscience maps are easier to locate, access, and use than non-standardized geoscience maps, neither are considered suitably easy to accommodate widespread use.

Respondents heavily favor geoscience maps in digital rather than hardcopy format (question 24). Therein, responses indicate GIS formats are preferred over PDF formats, though both are valued. Only 7 percent of respondents considered GIS and PDF map formats to be "not important." In contrast, hardcopy maps were deemed "very important" by only 18 percent, "somewhat important" by 49 percent, and "not important" by 33 percent of the respondents.

FINDING 9: The community overwhelmingly favor geoscience maps in digital rather than hardcopy format. Therein, the community prefers GIS formats over PDF formats, though both are valued.

Question 25 asked respondents whether they would find a single online location in which to search for and access geoscience maps beneficial to their work. Respondents "strongly agree" $(77 \%)$ that they would find such an online location useful, with another 20 percent of respondents indicating they "somewhat agree" with this statement. "Neither agree nor disagree," "somewhat disagree," and "strongly disagree" cumulatively garnered 3 percent of the responses.

FINDING 10: A single online repository that enables map makers and (or) map users to search for and access geoscience maps would be an extremely useful resource.

\section{Future Needs}

The fifth, and final, section of the survey questionnaire requested information about future needs of the broader scientific community as supported by the planetary geoscience mapping community and the needs of the geoscience mapping community as supported by the USGS-NASA Planetary Geologic Mapping Program. Respondents overwhelmingly agree (96 percent strongly and somewhat agree responses) that surface science investigations fundamentally rely on the spatial and temporal context established and refined by geoscience maps (question 26).

FINDING 11: Planetary geoscience investigations fundamentally rely on the spatial and temporal context established and refined by geoscience maps.

They also overwhelmingly agree ( $90 \%$ strongly and somewhat agree responses) that expedited production of standardized geoscience maps for areas of high interest and (or) relevance would benefit both scientific investigations and potential future exploratory mission planning (question 27).

FINDING 12: Expedited production of standardized planetary geoscience maps for areas of high interest and (or) relevance would benefit both scientific investigations and potential future exploratory mission planning.

Respondents agreed that multi-year geologic mapping campaigns that focus on making a series of maps for a particular body at a set map scale would be useful to the scientific community (question 28). Responses did not vary depending on respondent's planetary body of interest (question $28 \times$ question 7) (appendix 7).

FINDING 13: Multi-year geologic mapping campaigns that focus on making a series of maps for high priority bodies and terrains at relevant map scales are perceived as valuable future contributions to the scientific community.

Question 29 asked for input on respondent's likelihood of using topical mapping guidance on nine topics. Respondents generally indicated they were cumulatively "likely" over "not likely" to use mapping guidance for all topics: GIS tutorials ( $65 \%$ vs. $13 \%$ ), GIS templates ( $58 \%$ vs $14 \%$ ), description of map unit templates (54\% vs. $13 \%)$, method summaries $(53 \%$ vs. $10 \%$ ), short course in GIS mapping techniques (52\% vs. $16 \%$ ), map layout templates ( $52 \%$ vs. $14 \%$ ), correlation of map unit templates ( $51 \%$ vs. $15 \%)$, online mapping help 
boards (49\% vs. 11\%), and short course in photogeologic mapping (45\% vs. $23 \%$ ). If "somewhat likely" is added to "likely" responses, there is strong preference for the full range of mapping guidance.

FINDING 14: Planetary geoscience map makers and (or) users want more assistance with making geoscience maps, including tutorials, templates, and process documents.

\section{Optional Comments}

Question 30 asked respondents to provide any additional comments regarding planetary geoscience mapping efforts. These responses were optional and, to preserve the anonymity of respondents, were not included herein. 60 respondents opted to provide additional comments $(23 \%)$ with responses ranging in length and topic. However, responses broadly fell into one or more of four categories:

1. General support of the planetary geoscience mapping process and product, particularly for mission support.

2. Testaments on the need for web-based access to GISformatted geoscience maps.

3. Concerns about the difficulty in making standardized geoscience map products, especially as related to the perceived and perhaps actual high entry bar for new mappers.

4. Requests for easily accessible guidance on the preparation of standardized geoscience maps.

FINDING 15: The technical nuances of GIS are limiting factors in making standardized and non-standardized geoscience maps for broad-distribution and use by the planetary science community.

FINDING 16: The lengthy technical review process for standardized geoscience maps inhibits broader participation by interested community mappers.

FINDING 17: Planetary missions can benefit from strong support by appropriately scaled and themed planetary geoscience maps that implement standards but are also rapidly produced.

\section{Key Findings and Recommendations}

Seventeen key findings and their associated recommendations are listed below. These recommendations are a direct response to interpreted respondent data gathered by the questionnaire and represent various paths forward for the planetary science community. They can be addressed by multiple entities and initiatives in the community, either in series or parallel.
FINDING 1: Planetary geoscience maps are used more frequently by map makers, though respondents who never make maps still use them as a resource for their work and value them as critical contextual products.

RECOMMENDATION 1-Resources and support should continue to be provided to the planetary geoscience mapping community by both USGS and NASA to sustain and advance the production of these critical contextual products.

FINDING 2: Local to regional scale maps are valued more highly when hemispheric to global scale geoscience maps have already identified broadly-occurring units and established their spatial and temporal context.

RECOMMENDATION $2 A$ - The planetary science community should prioritize making standardized global to hemisphere scale geoscience maps for all Solar System bodies for which they do not already exist. Specifically, the community should prioritize making standardized geoscience maps at global to hemispheric scales of Mercury, Venus, Deimos, Phobos, Vesta, Ceres, Europa, all mid-sized Saturnian satellites, Pluto, and Charon.

RECOMMENDATION $2 B$ - The planetary science community should prioritize making local to regional scale geoscience maps of the Moon and Mars at consistent scales or within a narrow range of scales (between approximately $1: 50,000$ and $1: 500,000)$ to refine existing context and promote comparability.

FINDING 3: Geologic maps are perceived as the most relevant planetary geoscience map type, though geomorphologic, surficial, and compositional maps are also relevant map types.

RECOMMENDATION $3 A$ - The planetary geoscience mapping community should either effectively and consistently integrate geomorphologic, surficial, and compositional details into the preparation of both standardized and non-standardized geologic maps or consider, where appropriate, the production of separately focused (and titled) geomorphologic, surficial, or compositional maps.

RECCOMENDATION 3B-The USGS-NASA Planetary Geologic Mapping Program should, where appropriate, consider the technical means by which a wider variety of standardized geoscience maps could be published, including those that focus exclusively on geomorphology, surficial deposits, and compositional units across various bodies.

FINDING 4: Volcanic and impact-related units, features, and terrains are the most widely relevant for solid surface bodies throughout the Solar System, though there are units, features, and terrains that are perceived as relevant on bodies that have more diverse geologic histories.

RECOMMENDATION 4A-In addition to volcanic and impact-related terrains, Moon mapping efforts should target ancient crustal terrains.

RECOMMENDATION $4 B$ - In addition to volcanic and impact-related terrains, Mars mapping efforts should target 
fluvial/alluvial, stratified, ancient crustal, aqueously-altered, and aeolian terrains.

FINDING 5: Control to standard reference frame and objectivity in unit description are the two most important elements of planetary geoscience maps.

RECOMMENDATION $5 A$ - The planetary science community should prioritize generation of standard reference frames for solid surface bodies in the Solar System that do not currently have them and should prioritize generation of and documentation for controlled local to global scale data sets for use in making geoscience map products.

RECOMMENDATION $5 B$ - The planetary science community should strive for objectivity in the delineation and description of units presented in both standardized and non-standardized geoscience maps. Interpretations should be clearly separated and be directly supported by unit characteristics and contact relationships.

RECOMMENDATION 5C-Data acquired by new missions should adopt and adhere to coordinate systems and standard reference frames as defined by the International Astronomical Union (IAU). Such adoption and adherence critically facilitate the creation, co-location, and widespread use of derivative higher-order data products, including geoscience maps.

FINDING 6: Standardized and non-standardized geoscience maps are equally valued, though maps that follow cartographic standards are determined to be more effective at establishing context for the scientific community.

RECOMMENDATION 6A-The planetary science community should agree upon and make geoscience maps that adhere as closely as possible to a minimum set of cartographic standards for non-standardized geologic maps.

RECOMMENDATION 6B-The community is strongly encouraged to use existing advisory and working groups as a forum to discuss and determine minimum cartographic standards for all geoscience map products, both standardized and non-standardized. Once established, the community, in concert with the USGS, should offer open database schemas, symbol sets, tools, and tutorials needed to make a map that meets those minimum cartographic standards.

FINDING 7: Frequent geoscience map users and (or) makers are more knowledgeable of standard geoscience mapping processes, though in general there appears to be a lack of strong community knowledge related to application of standard geoscience mapping processes.

RECOMMENDATION 7A-The process of making, reviewing, and publishing the components of a standardized planetary geoscience map should be clearly documented and made available to the broadest part of the planetary science community possible.

RECOMMENDATION $7 B$ - When constructing a planetary geoscience map, regardless of publication venue, the planetary geoscience mapping community should search out resources related to the mapping process. The planetary geoscience community should implement the recommendations of these resources whenever possible and should use published products as guidance for map compilation.

RECOMMENDATION 7C-The planetary science community should ensure that current knowledge regarding the construction of planetary geoscience maps is not only thoroughly captured but specifically transferred to the broader scientific community and to the next generation of scientists and explorers.

RECOMMENDATION 7D-University and colleges should more broadly consider how to specifically include a rubric that captures the historic, scientific, and technical concepts and processes related to photogeologic mapping and the creation of planetary geoscience maps at undergraduate and graduate levels.

FINDING 8: Even though standardized geoscience maps are easier to locate, access, and use than non-standardized geoscience maps, neither are considered suitably easy to accommodate widespread use.

RECOMMENDATION 8-The community is strongly encouraged to explore the technical methods by which all planetary geoscience maps should be prepared and packaged to increase online discoverability and is strongly encouraged to enforce implementation of such methods once identified.

FINDING 9: The community overwhelmingly favors geoscience maps in digital rather than hardcopy format. Therein, the community prefers GIS formats are over PDF formats, though both are valued.

RECOMMENDATION 9A-Planetary geoscience maps, regardless of publication venue, should be made available in GIS and PDF formats.

RECOMMENDATION $9 B$ - Hardcopy prints of planetary geoscience maps should be curtailed, perhaps by limiting initial print runs, re-printing maps only when high demand makes it necessary, and (or) emphasizing "print-on-demand".

FINDING 10: A single online repository that enables map makers and (or) map users to search for and access geoscience maps would be an extremely useful resource.

RECOMMENDATION 10 - The community is strongly encouraged to explore the technical, managerial, and financial means by which all planetary geoscience maps regardless of publication venue could be searched for and accessed in a single location.

FINDING 11: Planetary geoscience investigations fundamentally rely on the spatial and temporal context established and refined by geoscience maps.

RECOMMENDATION 11A-The planetary geoscience mapping community should continue targeted investments in making and releasing planetary geoscience maps; including, in part, by addressing the recommendations presented herein.

RECOMMENDATION 11B - The planetary geoscience mapping community should continue to make both standardized and non-standardized geoscience maps and acknowledge 
that each fulfill important, complementary roles in defining and refining the geologic and stratigraphic context of solid surface bodies in the Solar System.

RECOMMENDATION $11 C$ - The planetary science community is encouraged to use and cite the relevant range of geoscience maps in peer-reviewed literature, including USGSpublished maps, when establishing context and rationale for investigation and (or) presenting scientific results.

FINDING 12: Expedited production of standardized planetary geoscience maps for areas of high interest and (or) relevance would benefit both scientific investigations and potential future exploratory mission planning.

RECOMMENDATION 12-NASA programs and current and upcoming missions are encouraged to work with the USGS-NASA Planetary Geologic Mapping Program to fully leverage available geoscience mapping resources in making mission-supportive and (or) mission-derivative geoscience maps and expediting the production of standardized geoscience maps that directly support the planning of future missions.

FINDING 13: Multi-year geologic mapping campaigns that focus on making a series of maps for high priority bodies and terrains at relevant map scales are perceived as valuable future contributions to the scientific community.

RECOMMENDATION 13-The community should consider what high priority bodies, regions, and map scales would be most beneficial and should investigate proposal and funding avenues with NASA program officers to execute these campaigns.

FINDING 14: Planetary geoscience map makers and (or) users want more assistance with making geoscience maps, including tutorials, templates, and process documents.

RECOMMENDATION 14A-The planetary geoscience mapping community should continue to build and make available tutorials, templates, and process documents to assist those members of the community who want to make planetary geoscience maps as part of their research.

RECOMMENDATIN 14B-The planetary geoscience mapping community should make available relevant templates and process documents that improve the transparency of the generation and production processes of planetary geoscience maps for those members of the community who use planetary geoscience maps as part of their research.

FINDING 15: The technical nuances of GIS are limiting factors in making standardized and non-standardized geoscience maps that are intended to be broadly-distributed and used by the planetary science community.

RECOMMENDATION 15A-The planetary geoscience mapping community should not only continue to make and release standardized and non-standardized map product in GIS format but also build and make available GIS tutorials, best practices, and process documents to aid the development of those products and reduce barriers to using GIS methods.
RECOMMENDATION 15B-The planetary geoscience mapping community should prioritize the inclusion, on an as needed basis, of GIS specialists on mapping projects to help make GIS-based geoscience maps in a timely and effective manner.

FINDING 16: The lengthy technical review process for standardized geoscience maps inhibits broader participation by interested community mappers.

RECOMMENDATION 16A-The USGS-NASA Planetary Geologic Mapping Program is encouraged to assess ways in which the technical review process can be streamlined without sacrificing product quality.

RECOMMENDATION 16B-Map makers and technical reviewers are encouraged to be intimately aware of the standardized geoscience mapping process and to complete review obligations in a thorough and timely manner.

RECOMMENDATION 16C - The process for making standardized geoscience maps, particularly the process of technical review and edit, needs to be thoroughly documented, broadly advertised, and made easily available for implementation.

FINDING 17: Planetary missions can benefit from strong support by appropriately scaled and themed planetary geoscience maps that implement standards but are also rapidly produced.

RECOMMENDATION 18-The USGS-NASA Planetary Geologic Mapping Program and missions should work more closely to ensure that planetary geoscience map products are created with specifications that strongly support and enhance mission goals in the short- and long-term.

\section{Next Steps}

Until now, there has been no modern assessment of the planetary geoscience mapping community for the following: (1) the investment value of geoscience map products and processes, (2) a future strategy that ensures appropriate prioritization of mapping efforts across all solid surface bodies in the Solar System, and (3) an evaluation of whether geoscience maps adequately meet the scientific and technical needs of the broadest part of the planetary science community possible. The findings and recommendations listed in this document begin an important community discussion regarding priorities for the creation and use of planetary geoscience maps. These results, and subsequent, separate discussions, mark an important effort toward filling a void in the aforementioned lack of modern assessment of the status and future needs of planetary geoscience mapping community. The findings revealed by this survey validate the need and usefulness of planetary geoscience map products and highlight areas where the planetary geoscience mapping community and the USGS-NASA Planetary Geologic Mapping Program can improve and streamline processes and products. The resultant recommendations can 
help to strengthen the planetary geoscience community and to compel modernization in the creation, access, and use of geoscience map products.

The survey results convey a positive return on the investment made by NASA into the USGS-NASA Planetary Geologic Mapping Program by confirming planetary geoscience map products as critical contextual products for the planetary science community. The results also identify a set of highpriority data, services, and online searching and accessing requirements to inform crucial planning for the future of planetary geoscience mapping. The audiences of this document, who are the strategic and programmatic decision makers, scientific and technical coordinators and facilitators, planetary geoscience map makers, and planetary geoscience map users, should all assess both the needs of their individual audiences and the actions they can provide in response to the recommendations herein. Each audience is encouraged, individually and collectively, to seek opportunities to communicate the value, needs, and methodology of planetary geoscience mapping and to explore methods of engaging other audiences in response to one or more recommendations stated in this document. Innovative and sustained actions are integral to the improvement and future trajectory of a geoscience mapping community to ensure reliable, relevant, and robust map products are available for use in planetary sciences and exploration efforts.

\section{References Cited}

Anderson, R.B. and Bell J.F. III, 2010, Geologic mapping and characterization of Gale Crater and implications for its potential as a Mars Science Laboratory landing site: Mars Journal, v. 5, p. 76-128, https://doi.org/10.1555/ mars.2010.0004.

Grolier, M.J., 1970, Geologic map of the Apollo landing site 2 (Apollo 11), part of Sabine D region, southwestern Mare Tranquilitatis: U.S. Geological Survey Miscellaneous Geologic Investigations Map I-619, 1:25,000 scale.

Hamilton, V.E., Hoehler, T., Eigenbrode, J., Rafkin, S., Withers, P., Ruff, S., Yingst, R., Lim, D., Whitley, R., Beaty, D., Diniega, S., Hays, L., Zurek, R., 2015, Mars Scientific Goals, Objectives, Investigations, and Priorities: Mars Exploration Program Analysis Group (MEPAG), 75 p.

Hendrix, A.R., Hurford, T.A., Barge, L.M., Bland, M.T., Bowman, J.S., Brinckerhoff, W., Buratti, B.J., Cable, M.L., Castillo-Rogez, J., Collins, G.C., Diniega, S., German, C.R., Hayes, A.G., Hoehler, T., Hosseini, S. Howett, C.J.A., McEwen, A.S., Neish, C.D., Neveu, M., Nordheim, T.A., Patterson, G.W., Patthoff, D.A., Phillips, C., Rhoden, A., Schmidt, B.E., Singer, K.N., Soderblom, J.M., and Vance, S.D., 2018, The NASA Roadmap to Ocean Worlds: Astrobiology, v. 19, no. 1, 27 p., https://doi.org/10.1089/ast.2018.1955.
Loizeau, D., Mangold, N., Poulet, F., Bibring, J-P, Gendrin, A., Ansan, V., Gomez, C., Godet B., Langevi, Y., Masson, P., and Nuekum, G., 2007, Phyllosilicates in the Mawrth Vallis region of Mars: Journal of Geophysical Research, v. $112,20 \mathrm{p}$.

National Research Council, 2011, Vision and Voyages for Planetary Science in the Decade 2013-2022: Washington, DC, The National Academies Press, 398 p. https://doi. org/10.17226/13117.

Skinner, J.A., Jr., Huff, A.E., Fortezzo, C.M., Gaither, T., Hare, T.M., Hunter, M.A., and Buban, H., 2018, Appendices for planetary geologic mapping--program status and future needs: U.S. Geological Survey data release, https://doi. org/10.5066/P9PQCENT.

Spencer, E.W., 2000, Geologic Maps-A practical guide to the preparation and interpretation of geologic maps $(2 \mathrm{~d} \mathrm{ed}$.): Long Grove, Illinois, Waveland Press, 184 p.

Tanaka, K.L., Skinner, J.A., Jr., Dohm, J.M., Irwin, R.P., III, Kolb, E.J., Fortezzo, C.M., Platz, T., Michael, G.G., and Hare, T.M., 2014, Geologic map of Mars: U.S. Geological Survey Scientific Investigations Map 3292, scale 1:20,000,000, pamphlet 43 p., https://doi.org/10.3133/ $\operatorname{sim} 3292$.

U.S. Congress, 1992, National Geologic Mapping Act: U.S. Congress, $102^{\text {nd }}$, H.R. 2763.

Varnes, D.J., 1974, The Logic of Geological Maps with Reference to Their Interpretation and Use for Engineering Purposes: U.S. Geological Survey Professional Paper 837, 48 p.

Williams, D.A., Yingst, R.A., Garry, W.B., 2014, Introduction-The geologic mapping of Vesta: Icarus, v. 244, p. 1-12, https://doi.org/10.1016/j.icarus.2014.03.001. 


\section{Appendixes}

The survey questionnaire and summary responses are contained in appendix 1 and 2 respectively. Data pertaining to the cross correlation of survey questions (appendixes 3 through 7 ) are contained in a separate data release. This data release can be found online at https://doi.org/10.5066/P9PQCENT 


\title{
Appendix 1. Survey Questionaire
}

\author{
Intent and Guidance
}

Please take a few minutes to give us your opinion of planetary geoscience maps!

We are working hard to ensure that planetary geoscience maps meet the needs of the broadest part of the scientific community possible. Your responses will help identify areas of improvement.

\section{Maximum of 30 questions \\ $<10$ minutes \\ Responses are anonymous}

Prepared by the Mapping and Planetary Spatial Infrastructure Team (MAPSIT). Collated responses will be posted on the MAPSIT website (http://www.Ipi.usra.edu/mapsit) by August 31, 2017.

Terms used herein:

Geoscience maps-Maps that discretely delineate and describe units or terrains using base maps (for example, geologic, structural, geomorphological, stratigraphic maps).

Base maps-Derived data products upon which units or terrains may be identified (for example, controlled mosaics, degital terrain models, elemental composition).

Standardized maps - Geoscience maps published by USGS that require adherence to cartographic standards, conventions, and principles.

Non-standardized maps-Geoscience maps published by other venues (for example, peer review journal, thesis/dissertation, special issue, book chapter) that are not required to, but might, adhere to cartographic standards, conventions, and principles.

When not specified, assume that "geoscience maps" indicate both standard and non-standard products.

Figure 1.1. Cover and instructions to survey questionnaire. 


\section{Respondent Details [required]}

\section{Your organization?}

University or College

Federal institution

Non-teaching, non-governmental research institution

Private industry

Other

\section{Your stage of career?}

Undergraduate student

Graduate student

Post-doc

Early career professional

Middle career professional

Late career professional

Other

\section{Your discipline? [select up to three]}

Atmospheric science

Biology/Astrobiology/Exobiology

Education

Engineering

Geodesy/Photogrammetry

Geochemistry/Cosmochemistry/Petrology

Geographic Information Sciences

Geology/Geomorphology

Geophysics

Information technology

Other

Figure 1.2. Questions 1 through 3 on the topic of respondent career and organizational affiliation.

\section{Your type of work? [select up to three]}

Research

Computer science

Education (primary or secondary instruction)

Education (university or college)

Image processing/archiving/dissemination

Mission planning

Mission, instrument, or payload concept development

Public outreach

Programmatic and/or institutional management

Other

5. Your major funding source(s)? [select up to two]

NASA programs

Non-NASA U.S. Federal Programs European Space Agency (ESA)

programs

Non-ESA EU Programs

College/University

National Science Foundation (NSF)

Other

6. Are you involved in active mission planning, mission operations, and/or specific mission-affiliated research?

Yes

No

Figure 1.3. Questions 4 through 6 on the nature of respondent work and funding. 
7. Relevance of the following planetary bodies/systems to your work?

Mercury
Venus
Earth
Moon
Mars (including Deimos
and Phobos)
Main belt asteroids
Jovian system
Saturnian system
Uranian/Neptunian
systems
Pluto (including Charon)
Other

8. Relevance of the following data types to your work?

Topography/DTM
Orthoimages and image
mosaics
$\begin{aligned} & \text { Controlled image } \\ & \text { mosaics }\end{aligned}$
$\begin{aligned} & \text { Elemental } \\ & \text { composition/Mineral } \\ & \text { maps }\end{aligned}$
$\begin{aligned} & \text { Thermophysical property } \\ & \text { map }\end{aligned}$
RADAR
Other

Figure 1.4. Questions 7 and 8 on the topic of relevant planetary bodies or systems and data types. 
9. Importance of the following software/services to your work?

Geographic Information Systems

(e.g., ArcGIS, QGIS)
PDS servers

Web-map services

Image processing (e.g.,

ISIS, ENVI)

10. Do you have a hard-copy USGS-publishing planetary geologic map in your office or workspace?

Yes

No

12. Frequency that you use geoscience maps

for your work?
Often
Occasionally
Never

Figure 1.5. Question 9 through 12 on the topics of software services and respondent role in use or creation of geoscience maps.

\section{Exit Page}

13. I do not use geoscience maps for my work because:

Check all that apply

Maps do not have scales that support my work

Maps are not located in regions that support my work

Maps are difficult to obtain

Maps are not objective enough to support my work

Maps are not in a format that is useful to my work

Maps are just not applicable to my work

14. Additional comments?

Figure 1.6. Questions 13 and 14 on why respondents do not use geoscience maps, prompted by a "never" response to Question 12 (frequency of geoscience map use).
11. Frequency that you create geoscience maps as by-product or final product for your work?

Often

Occasionally

Never 


\section{Map Scale and Topics}

15. Relevance of the following map scales to your work?

Very local scales
Local to regional scales
Regional to hemispheric
scales
Hemispheric to global
scales

16. Relevance of the following planetary geoscience map types to your work?

Geologic maps
Geomorphologic and
landform maps
Surficial geology maps
Geophysical maps
Compositional maps
Structural maps
Hydrogeologic maps
Landing site and/or
traverse maps
Other

Figure 1.7. Questions 15 and 16 on the topics of map scale and geoscience map types used. 
17. Relevance of the following unit, terrian, and /or feature types to your work?

\begin{tabular}{|c|c|c|c|}
\hline & Very relevant & Somewhat relevant & Not relevant \\
\hline \multicolumn{4}{|l|}{ Stratified } \\
\hline \multicolumn{4}{|l|}{ Ancient crustal } \\
\hline \multicolumn{4}{|l|}{ Aeolian } \\
\hline \multicolumn{4}{|l|}{ Aqueously-altered } \\
\hline \multicolumn{4}{|l|}{ Mass-wasting } \\
\hline \multicolumn{4}{|l|}{ Fluvial/alluvial } \\
\hline \multicolumn{4}{|l|}{ Volcanic } \\
\hline \multicolumn{4}{|l|}{ Impact-related } \\
\hline \multicolumn{4}{|l|}{ Densely-faulted } \\
\hline \multicolumn{4}{|l|}{ Glacial/periglacial } \\
\hline Other & & & \\
\hline
\end{tabular}

Figure 1.8. Question 17 on the relevance of geologic process to respondent work.

\section{Map Use}

\section{Reminder:}

- Standardized maps-Geoscience maps published by the U.S. Geological Survey (USGS) that require adherence to cartographic standards, conventions, and principles.

- Non-standardized maps-Geoscience maps published by other venues (for example, peer review journal, thesis/dissertation, special issue, book chapter) that are not required to, but might, adhere to cartographic standards, conventions, and principles.

18. Importance of the following geoscience map publications to your work?

USGS-published maps
Peer reviewed journal
maps
Thesis/dissertation maps
Book chapter maps
Conference abstract
maps

Figure 1.9. Questions 18 through 20 on the importance of map publication source, elements, and the use of non-standardized maps that contain standard symbol sets and formats. 
19. Importance of the following geoscience map elements to your work?

Consistent use of
symbols
Consistent preparatory
methods
$\begin{aligned} & \text { Objectivity of unit } \\ & \text { description }\end{aligned}$
Comparability in look
and feel
$\begin{aligned} & \text { Comparability in map } \\ & \text { scale }\end{aligned}$
Control to standard
coordinate system

20. Non-standardized geoscience maps that implement standard cartographic symbols sets and formats are useful than those that do not.

More

Equally

Less

Figure 1.9. - continued.

21. Relevance of geoscience maps to establishing context for the scientific community?

Very relevant
Nondardized maps

22. You are knowledgeable of and can confidently apply standard geologic mapping processes.

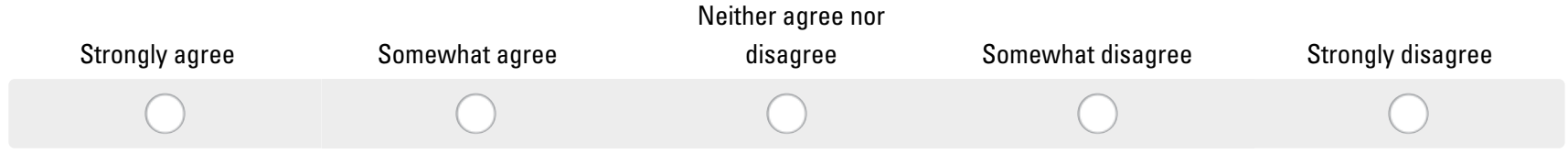

Figure 1.10. Question 21 on the use of geoscience maps to establish context and question 22 on respondent knowledge of map standard mapping methods. 


\section{Map Access}

Reminder:

- Standardized maps-Geoscience maps published by the U.S. Geological Survey (USGS) that require adherence to cartographic standards, conventions, and principles.

- Non-standardized maps-Geoscience maps published by other venues (for example, peer review journal, thesis/dissertation, special issue, book chapter) that are not required to, but might, adhere to cartographic standards, conventions, and principles.

\section{Ease of locating, accessing and using planetary geoscience maps.}

Standardized maps
Non-standardized maps
24.Importance of the following geoscience map formats to your work?
GIS (vector) format
PDF format
Hard-copy format

25. You would find it useful to search for the access geoscience maps in online locations.

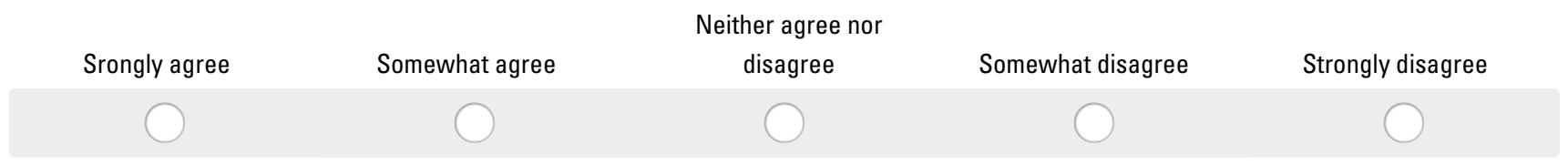

Figure 1.11. Questions 23 through 24 on respondent access to geoscience maps, importance of maps to respondent work and the importance of a single, online geoscience map repository.

\section{Future Needs}

26. Surface science investigations fundamentally rely on spatial and temporal context established and refined by geoscience maps.

$$
\text { Strongly agree }
$$

Somewhat agree

$$
\text { Neither agree nor }
$$

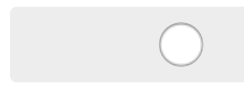

$$
\text { disagree }
$$

Somewhat disagree

Strongly disagree

27. Expedited production of standardized geoscience maps for areas of high interest and/or relevance would benefit both scientific investigations and potential future exploratory mission planning.

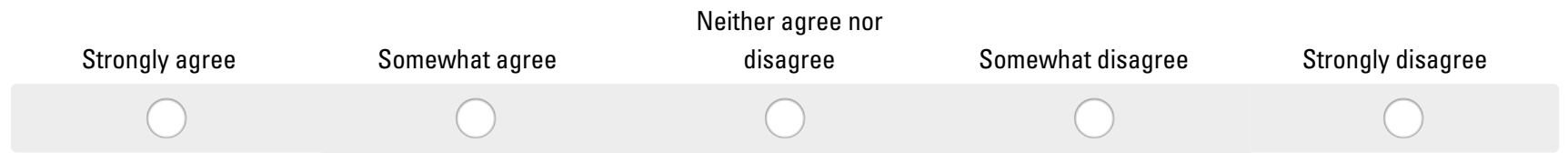

Figure 1.12. Questions 26 through 29 on topics concerning the future needs of the geoscience map community. 
28. Multi-year geologic mapping campaigns that focus on creating a series of maps for a particular body at a set map scale would be useful for the scientific community.

Strongly agree

Somewhat agree

Neither agree nor

disagree

Somewhat disagree

Strongly disagree

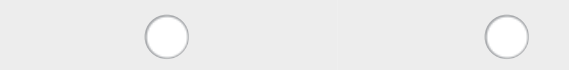

29. Likelihood of using topical mapping guidance.

GIS tutorials
Method summaries
GIS templates
Description of map unit
templates
Correlation of map unit
templates
Map layout templates
Short course in
photogeologic mapping
Short course in GIS
mapping techniques
Online mapping help
boards

Figure 1.12.-continued.

\section{Parting words}

30. Please provide any additional comments regarding planetary geoscience mapping efforts.

Figure 1.13. Question 30 providing respondents the ability to comment regarding planetary geoscience mapping efforts. 


\section{Appendix 2. Summary Responses}

\section{Your organization?}

Answered: 265

Skipped: 0

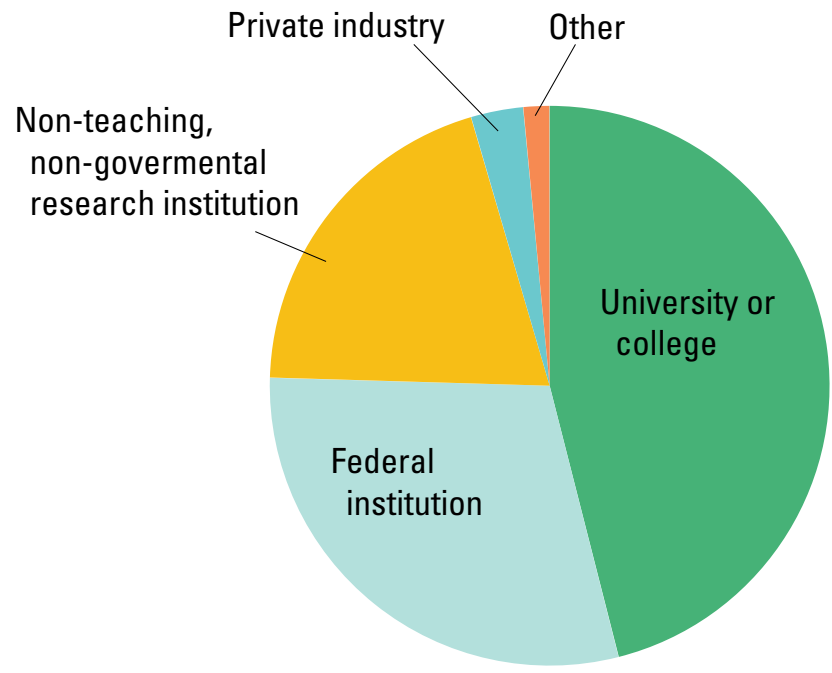

\begin{tabular}{lcc}
\hline ANSWER CHOICES & RESPONSES & \\
University or college & $46 \%$ & 122 \\
\hline $\begin{array}{l}\text { Federal institution } \\
\begin{array}{l}\text { Non-teaching, non-govermental } \\
\text { research institution }\end{array}\end{array}$ & $29 \%$ & 78 \\
\hline $\begin{array}{l}\text { Private industry } \\
\text { Other }\end{array}$ & $3 \%$ & 53 \\
\hline TOTAL & $2 \%$ & 8 \\
\hline
\end{tabular}

Figure 2.1. Responses showing a majority of respondent work based in university, college, or federal institutions (question 1).

\section{Your stage of career?}

Answered: $265 \quad$ Skipped: 0

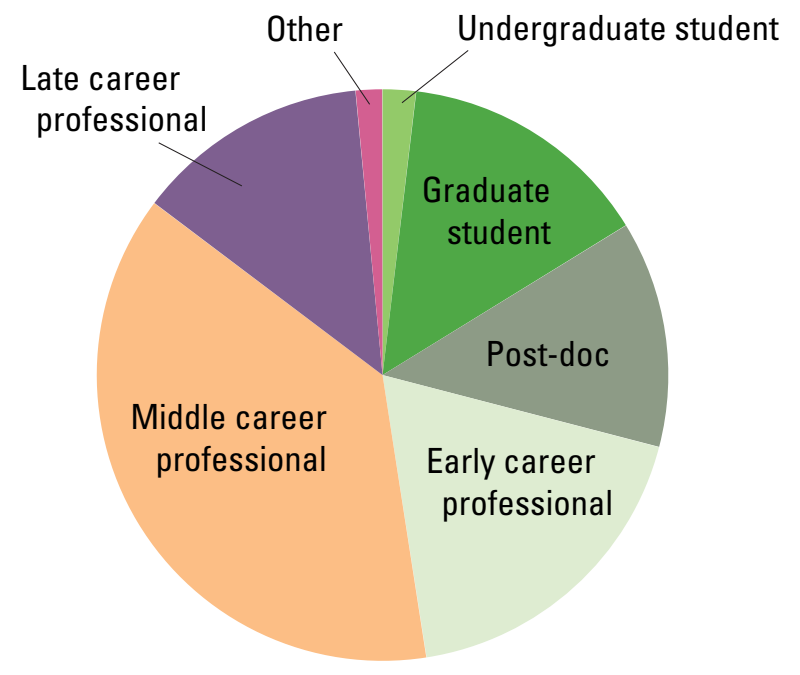

\begin{tabular}{lcc} 
ANSWER CHOICES & RESPONSES \\
\hline Undergraduate student & $2 \%$ & 5 \\
\hline Graduate student & $14 \%$ & 38 \\
\hline Post-doc & $13 \%$ & 34 \\
\hline Early career professional & $18 \%$ & 49 \\
\hline Middle career professional & $38 \%$ & 100 \\
\hline Late career professional & $13 \%$ & 35 \\
\hline Other & $2 \%$ & 4 \\
\hline TOTAL & & 265
\end{tabular}

Figure 2.2. Responses indicating stages of career in which respondents reside (question 2 ). 


\section{Your discipline? [select up to three]}

Answered: $265 \quad$ Skipped: 0

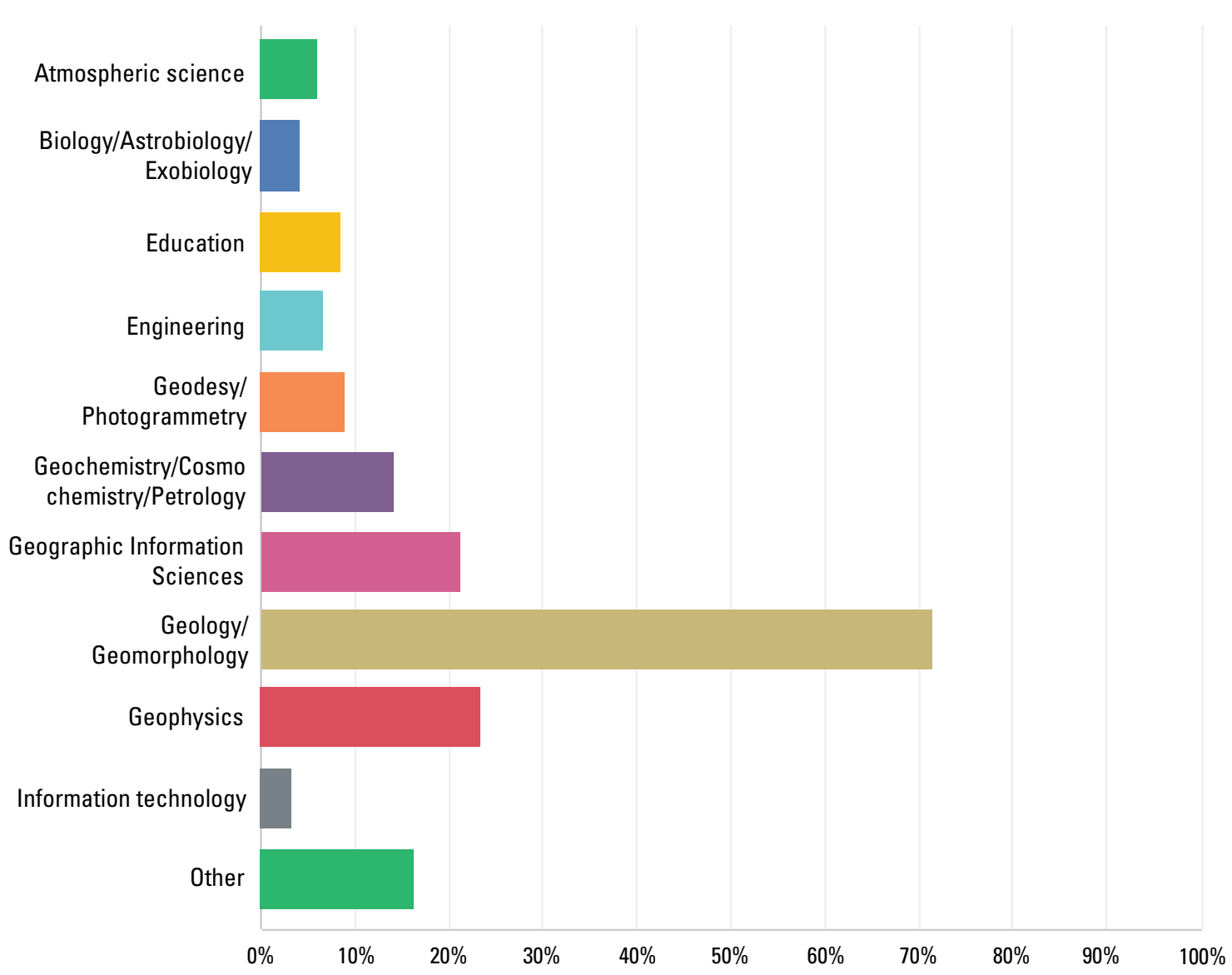

\begin{tabular}{llc}
\hline ANSWER CHOICES & RESPONSES & 16 \\
\hline Atmospheric science & $6 \%$ & 11 \\
\hline Biology/Astrobiology/Exobiology & $4 \%$ & 23 \\
\hline Education & $9 \%$ & 18 \\
\hline Engineering & $7 \%$ & 24 \\
\hline Geodesy/Photogrammetry & $9 \%$ & 37 \\
\hline Geochemistry/Cosmochemistry/Petrology & $14 \%$ & 56 \\
\hline Geographic Information Sciences & $21 \%$ & 189 \\
\hline Geology/Geomorphology & $71 \%$ & 62 \\
\hline Geophysics & $23 \%$ & 9 \\
\hline Information technology & $3 \%$ & 43 \\
\hline Other & $16 \%$ & \\
\hline Total Respondents: 265 & & $2 \%$ \\
\hline
\end{tabular}

Figure 2.3. Respondents area of discipline as chosen through a selection of up to three choices (question 3). 


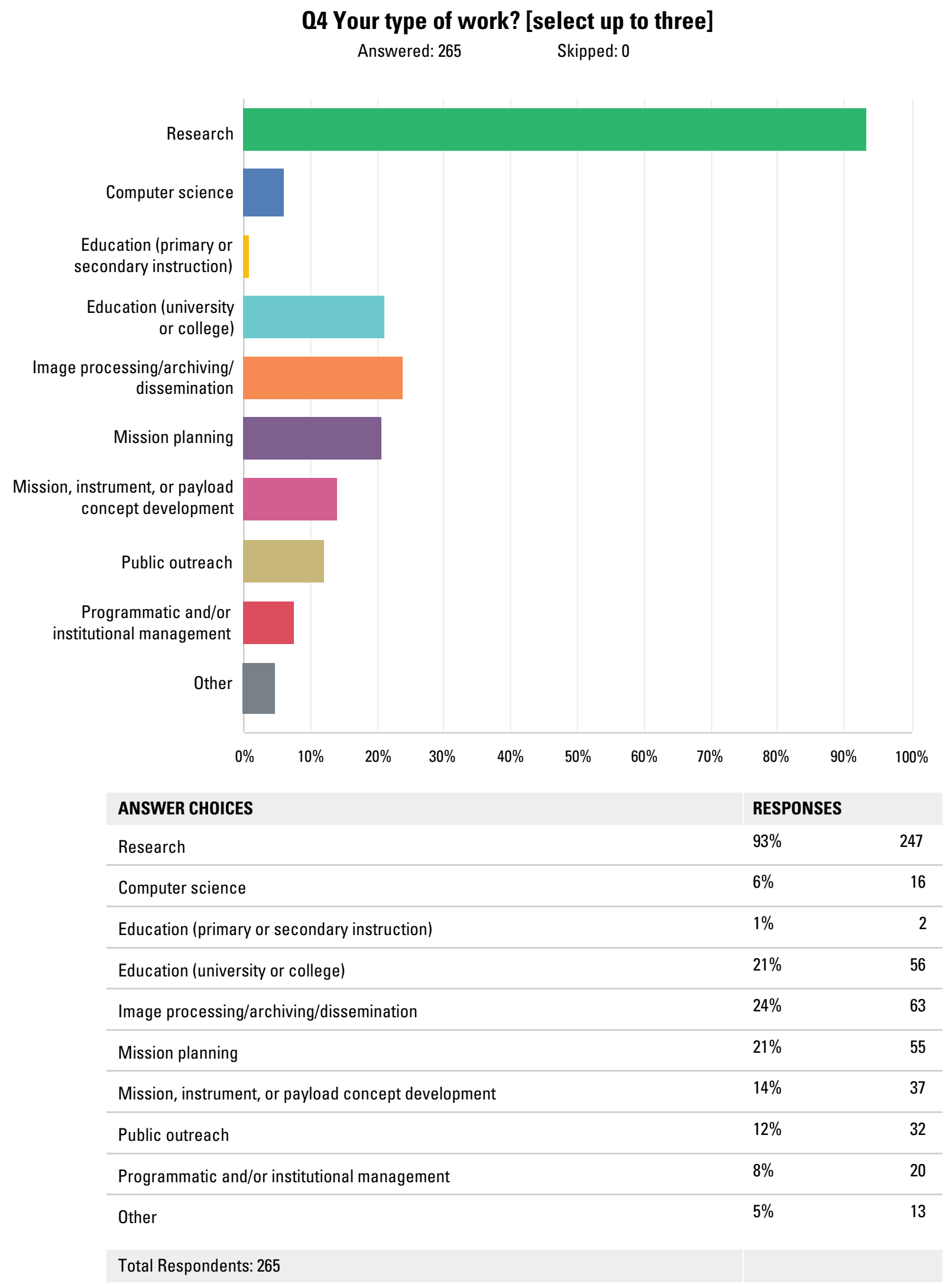

Figure 2.4. Respondents type of work as selected through three options (question 4). 


\section{Your major funding source(s)? [select up to two]}

Answered: 265

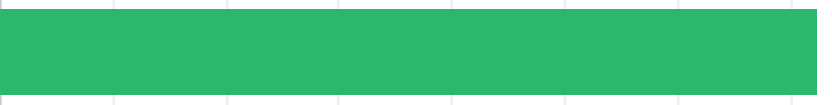

Non-NASA U.S.

Federal Programs

European Space Agency

(ESA) programs

Non-ESA EU Programs

College/University

National Science

Foundation (NSF)

Other
Skipped: 0

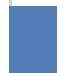

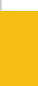

(n)
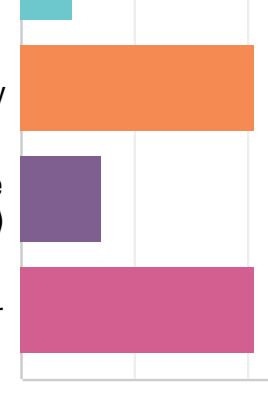

$20 \%$

$30 \%$

$40 \%$

$50 \%$

$60 \%$

$70 \%$

$80 \%$

$90 \% \quad 100 \%$

\section{ANSWER CHOICES}

\section{RESPONSES}

NASA programs

$72 \%$

192

Non-NASA U.S. Federal Programs

$4 \%$

11

ESA programs

$5 \%$

12

Non-ESA EU Programs

$5 \%$

12

College/University

$21 \%$

55

NSF

$7 \%$

19

Other

$21 \%$

55

Total Respondents: 265

Figure 2.5. Respondents source of funding (question 5). 
Planetary Geologic Mapping—Program Status and Future Needs

Q6 Are you involved in active mission planning, mission operations, and/or specific mission-affiliated research?

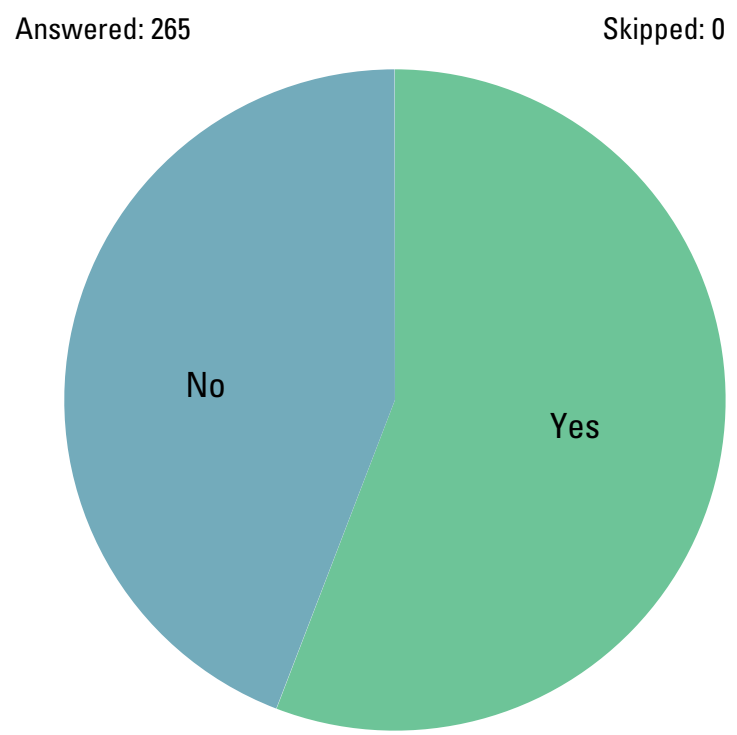

\begin{tabular}{llr} 
ANSWER CHOICES & RESPONSES & 148 \\
\hline YeS & $56 \%$ & 117 \\
\hline No & $44 \%$ & 265 \\
\hline TOTAL & & $26 \%$
\end{tabular}

Figure 2.6. Respondent involvement in active mission planning, operations, or affiliated research (question 6). 


\section{Relevance of the following planetary bodies/systems to your work?}

Answered: 265

Skipped: 0

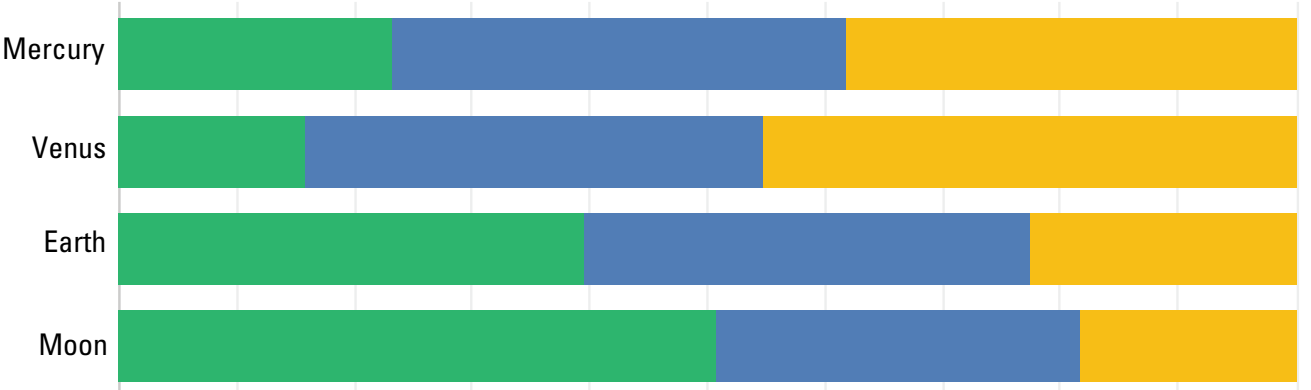

Mars (including Deimos and Phobos)

Main belt asteroids

Jovian system

Saturnian system

Uranian/Neptunian systems

Pluto (including Charon)

Other

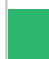

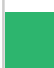
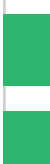


\section{Q8 Relevance of the following data types to your work?}

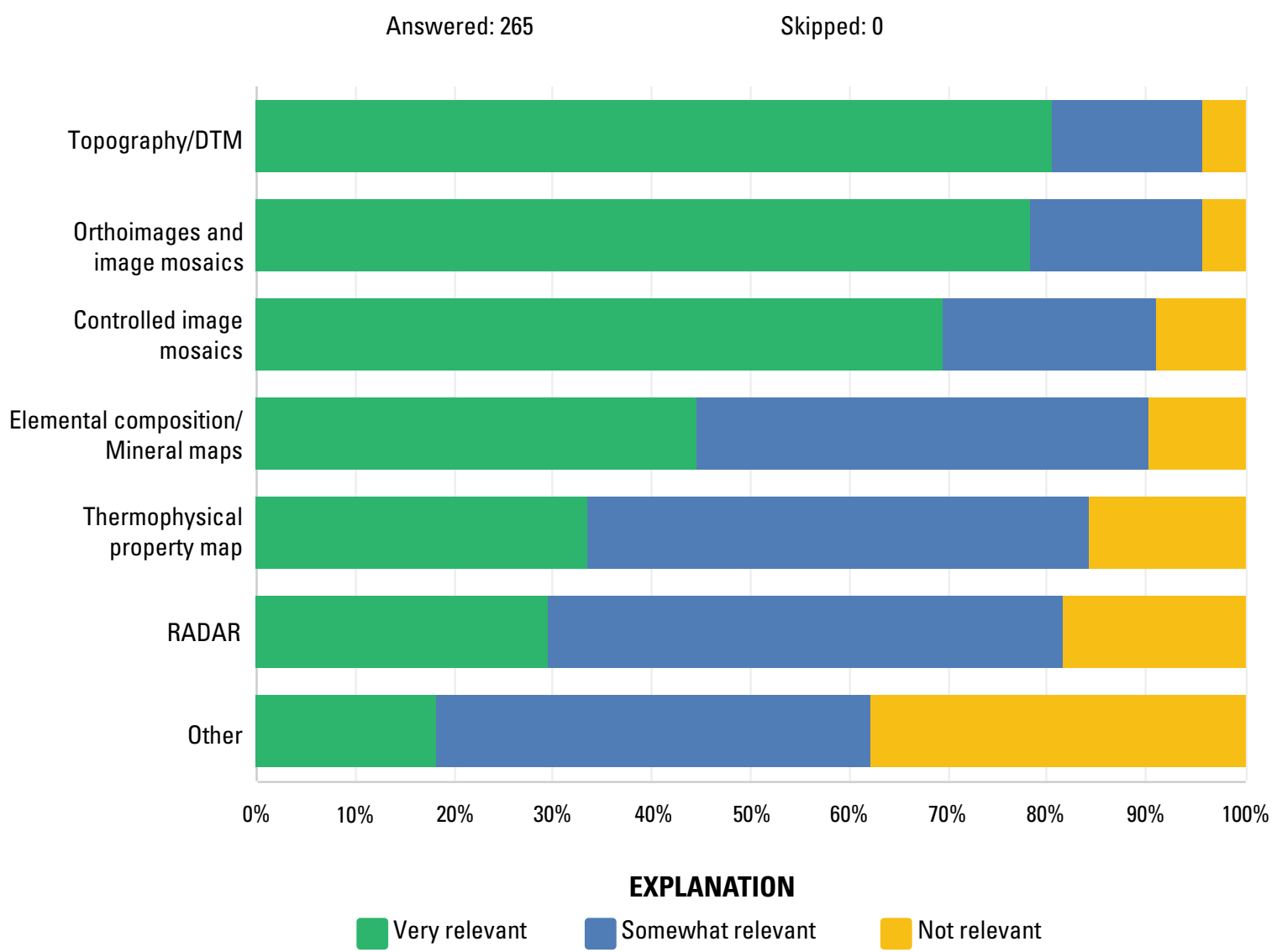

\begin{tabular}{|c|c|c|c|c|}
\hline DATA TYPES & VERY RELEVANT & SOMEWHAT RELEVANT & NOT RELEVANT & TOTAL \\
\hline Topography/DTM & $81 \%$ & $15 \%$ & $4 \%$ & \\
\hline Responses & 211 & 40 & 11 & 262 \\
\hline Orthoimages and image mosaics & $78 \%$ & $18 \%$ & $4 \%$ & \\
\hline Responses & 205 & 46 & 11 & 262 \\
\hline Controlled image mosaics & $69 \%$ & $22 \%$ & $9 \%$ & \\
\hline Responses & 180 & 56 & 23 & 259 \\
\hline Elemental composition/Mineral maps & $45 \%$ & $46 \%$ & $10 \%$ & \\
\hline Responses & 115 & 118 & 25 & 258 \\
\hline Thermophysical property map & $33 \%$ & $51 \%$ & $16 \%$ & \\
\hline Responses & 83 & 126 & 39 & 248 \\
\hline RADAR & $29 \%$ & $52 \%$ & $18 \%$ & \\
\hline Responses & 74 & 131 & 46 & 251 \\
\hline Other & $18 \%$ & $44 \%$ & $38 \%$ & \\
\hline Responses & 29 & 70 & 60 & 159 \\
\hline
\end{tabular}

Figure 2.8. Relevance of data type to respondent work (question 8). 


\section{Importance of the following software/services to your work?}

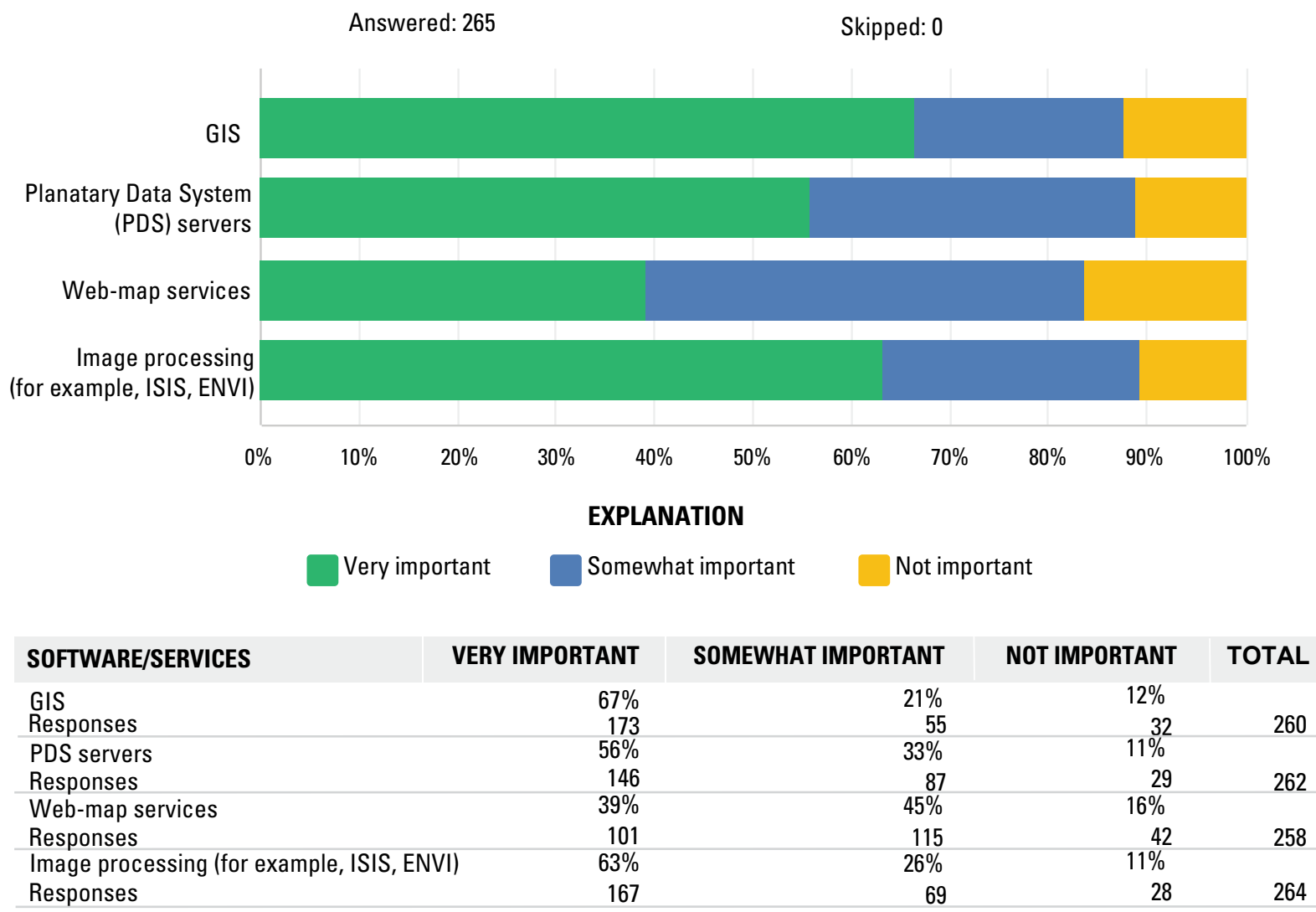

Figure 2.9. Importance of software and services to respondent work (question 9).

Q10 Do you have a hard-copy U.S. Geological Survey (USGS)-published planetary geologic map in your office or workspace?

Answered: $265 \quad$ Skipped: 0

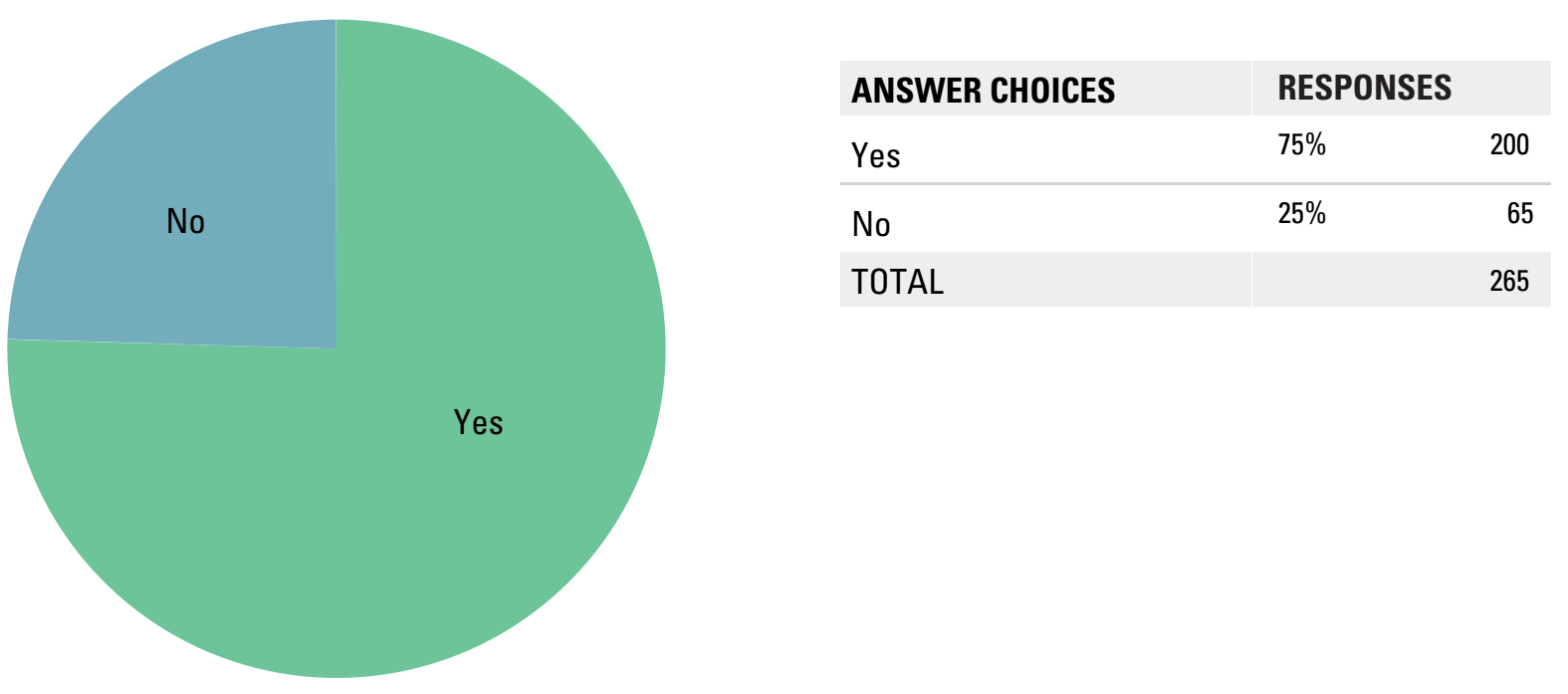

Figure 2.10. Presence of hard-copy USGS-published planetary geologic map in respondent workspace (question 10). 
011 Frequency that you create geoscience maps as by-product or final product for your work?

Answered: 265

Skipped: 0

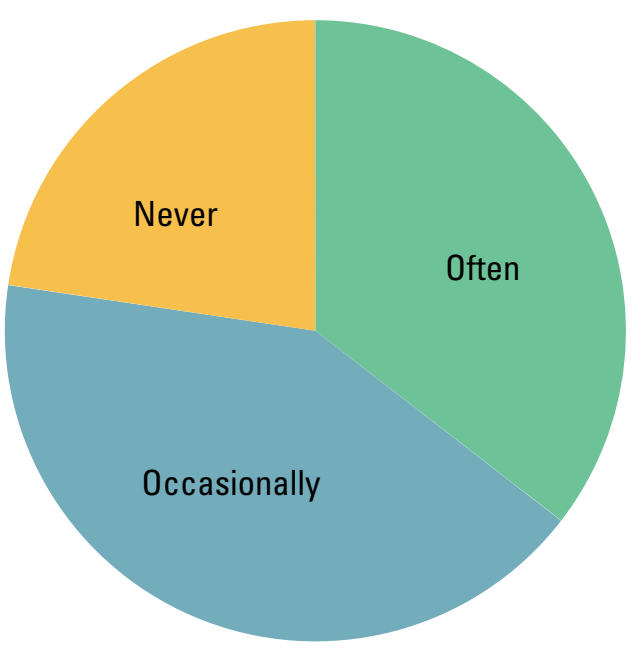

\begin{tabular}{lcc} 
ANSWER CHOICES & RESPONSES & \\
Often & $35 \%$ & 94 \\
\hline Occasionally & $42 \%$ & 111 \\
\hline Never & $23 \%$ & 60 \\
TOTAL & & 265
\end{tabular}

Figure 2.11. Frequency of geoscience map creation by respondents (question 11).

\section{Frequency that you use geoscience maps for your work?}

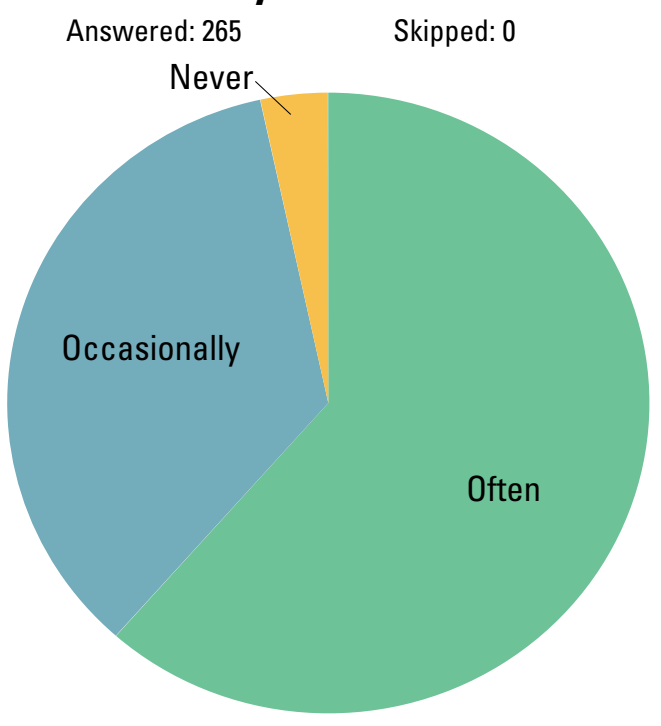

\begin{tabular}{llr} 
ANSWER CHOICES & RESPONSES & \\
\hline Often & $62 \%$ & 163 \\
\hline Occasionally & $35 \%$ & 93 \\
\hline Never & $3 \%$ & 9 \\
TOTAL & & 265 \\
\hline
\end{tabular}

Figure 2.12. Frequency of geoscience map use by respondents (question 12) 


\section{I do not use geoscience maps for my work because:}

Answered: 9

REASON

Maps do not have scales that support my work

Responses

Maps are not located in regions that support my work

Responses

Maps are difficult to obtain

Responses

Maps are not objective enough to support my work

Responses

Maps are not in a format that is useful to my work

Responses

Maps are just not applicable to my work

Responses
Skipped: 256

CHECK ALL THAT APPLY

TOTAL RESPONDENTS

Figure 2.13. Respondent response and reason for lack of geoscience map use (question 13)

\section{Relevance of the following map scales to your work?}

Answered: 246

Skipped: 19

Very local scales

Local to regional scales

Regional to hemispheric scales

Hemispheric to global scales

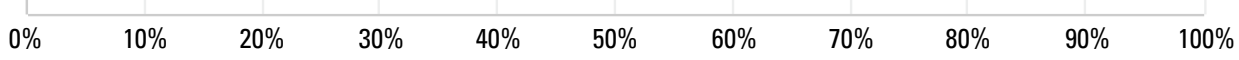

\section{EXPLANATION}

Very relevant

Somewhat relevant

Not relevant

\section{MAP SCALE}

Very local scales

Responses

Local to regional scales

Responses

Regional to hemispheric scales

Responses

Hemispheric to global scales

Responses

VERY RELEVANT
$64 \%$
156
$75 \%$
184
$58 \%$
142
$55 \%$
132

SOMEWHAT RELEVANT

$27 \%$

66

$22 \%$

54
$37 \%$

91

$36 \%$

86

\begin{tabular}{rr} 
NOT RELEVANT & TOTAL \\
$9 \%$ & \\
22 & 244 \\
$2 \%$ & \\
6 & 244 \\
$4 \%$ & \\
10 & 243 \\
$10 \%$ & \\
24 & 242 \\
\hline
\end{tabular}

Figure 2.14. Relevance of map scale to respondent work (question 15). 


\section{Relevance of the following planetary geoscience map types to your work?}

Answered: 246

Skipped: 19

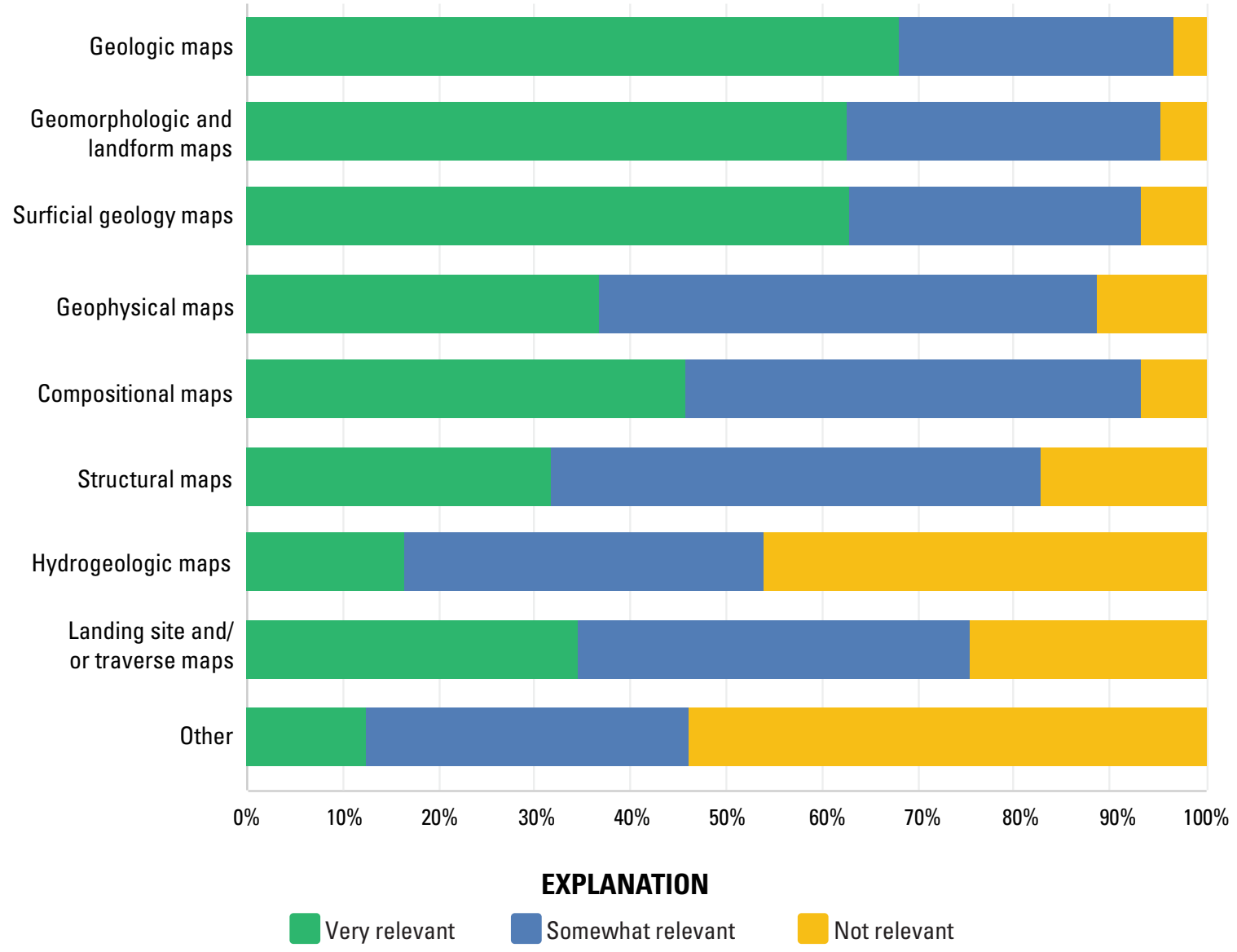

\begin{tabular}{|c|c|c|c|c|}
\hline MAP TYPES & VERY RELEVANT & SOMEWHAT RELEVANT & NOT RELEVANT & TOTAL \\
\hline Geologic maps & $68 \%$ & $29 \%$ & $3 \%$ & \\
\hline Responses & 166 & 70 & 8 & 244 \\
\hline Geomorphologic and landform maps & $63 \%$ & $33 \%$ & $5 \%$ & \\
\hline Responses & 152 & 80 & 11 & 243 \\
\hline Surficial geology maps & $63 \%$ & $31 \%$ & $7 \%$ & \\
\hline Responses & 152 & 74 & 16 & 242 \\
\hline Geophysical maps & $37 \%$ & $52 \%$ & $11 \%$ & \\
\hline Responses & 89 & 126 & 27 & 242 \\
\hline Compositional maps & $46 \%$ & $48 \%$ & $7 \%$ & \\
\hline Responses & 110 & 114 & 16 & 240 \\
\hline Structural maps & $32 \%$ & $51 \%$ & $17 \%$ & \\
\hline Responses & 76 & 123 & 41 & 240 \\
\hline Hydrogeologic maps & $16 \%$ & $38 \%$ & $46 \%$ & \\
\hline Responses & 39 & 89 & 109 & 237 \\
\hline Landing site and/or traverse maps & $35 \%$ & $41 \%$ & $25 \%$ & \\
\hline Responses & 83 & 98 & 59 & 240 \\
\hline Other & $12 \%$ & $34 \%$ & $54 \%$ & \\
\hline Responses & 18 & 49 & 78 & 145 \\
\hline
\end{tabular}

Figure 2.15. Relevance of geoscience map type to respondent work (question 16). 


\section{Relevance of the following unit, terrain, and/or feature types to your work? \\ Answered: $245 \quad$ Skipped: 20}

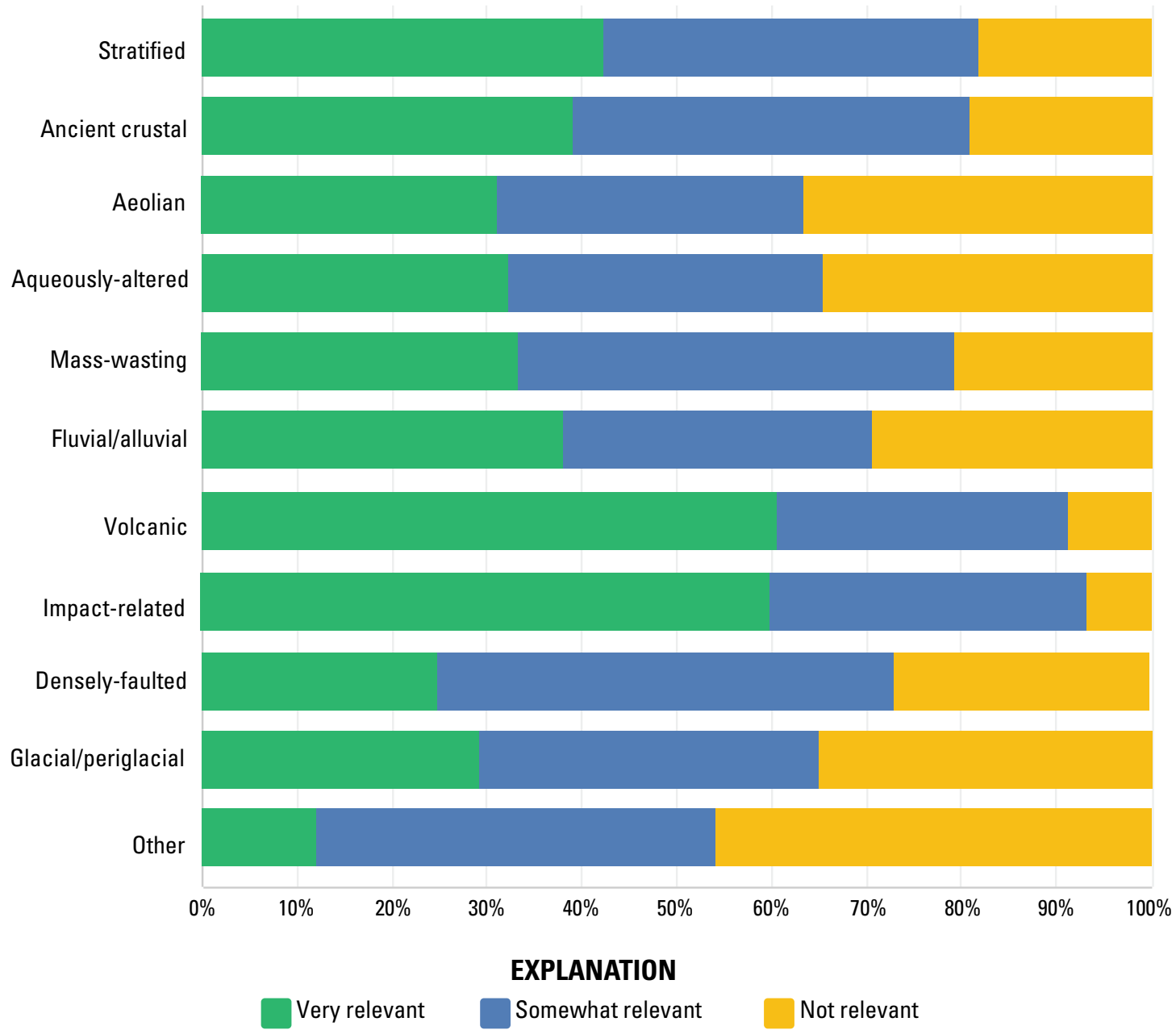

\begin{tabular}{lrrr|r} 
UNIT, TERRAIN, AND/OR FEATURE & VERY RELEVANT & SOMEWHAT RELEVANT & NOT RELEVANT & TOTAL \\
Stratified & $42 \%$ & $39 \%$ & $18 \%$ & \\
Responses & 101 & 94 & 43 & 238 \\
\hline Ancient crustal & $39 \%$ & $42 \%$ & $19 \%$ & \\
Responses & 94 & 100 & 46 & 240 \\
\hline Aeolian & $31 \%$ & $32 \%$ & $37 \%$ & \\
Responses & 74 & 77 & 87 & 238 \\
\hline Aqueously-altered & $32 \%$ & $33 \%$ & $34 \%$ & \\
Responses & 77 & 79 & 82 & 238 \\
\hline Mass-wasting & $33 \%$ & $46 \%$ & $21 \%$ & \\
Responses & 79 & 109 & 49 & 237 \\
\hline Fluvial/alluvial & $38 \%$ & $32 \%$ & $29 \%$ & \\
Responses & 91 & 77 & 70 & 238 \\
\hline Volcanic & $61 \%$ & $31 \%$ & $9 \%$ & \\
Responses & 146 & 74 & 21 & 241 \\
\hline Impact-related & $60 \%$ & $33 \%$ & $7 \%$ & \\
Responses & 146 & 81 & 16 & 243 \\
\hline Densely-faulted & $25 \%$ & $48 \%$ & $27 \%$ & \\
Responses & 59 & 114 & 63 & 236 \\
\hline Glacial/periglacial & $29 \%$ & $36 \%$ & $35 \%$ & 238 \\
Responses & 70 & 85 & 83 & 238 \\
\hline Other & $12 \%$ & $42 \%$ & $46 \%$ & 140 \\
Responses & 17 & 59 & 64 & \\
\hline
\end{tabular}

Figure 2.16. Relevance of unit, terrain and (or) feature type to respondent work (question 17). 


\section{Importance of the following geoscience map publications to your work?}

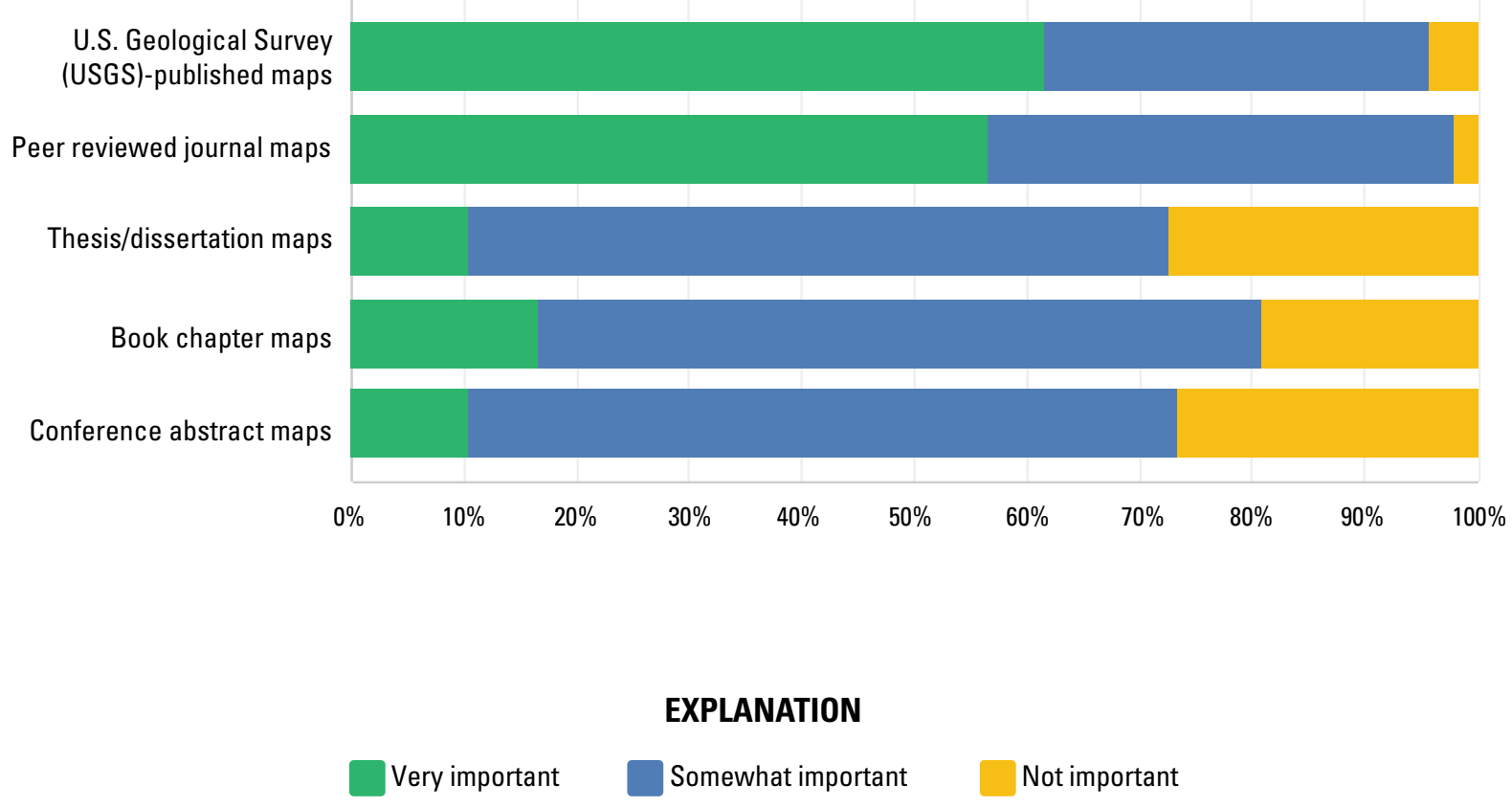

\begin{tabular}{|c|c|c|c|c|}
\hline GEOSCIENCE MAP PUBLICATIONS & VERY IMPORTANT & SOMEWHAT IMPORTANT & NOT IMPORTANT & TOTAL \\
\hline USGS-published maps & $62 \%$ & $34 \%$ & $4 \%$ & \\
\hline Responses & 149 & 83 & 10 & 242 \\
\hline Peer reviewed journal maps & $57 \%$ & $41 \%$ & $2 \%$ & \\
\hline Responses & 137 & 100 & 5 & 242 \\
\hline Thesis/dissertation maps & $11 \%$ & $62 \%$ & $27 \%$ & \\
\hline Responses & 25 & 148 & 65 & 238 \\
\hline Book chapter maps & $17 \%$ & $64 \%$ & $19 \%$ & \\
\hline Responses & 40 & 154 & 46 & 240 \\
\hline Conference abstract maps & $11 \%$ & $63 \%$ & $26 \%$ & \\
\hline Responses & 25 & 150 & 63 & 238 \\
\hline
\end{tabular}

Figure 2.17. Importance of geoscience map publication type to respondent work (question 18). 


\section{Importance of the following geoscience map elements to your work?}

Answered: $244 \quad$ Skipped: 21

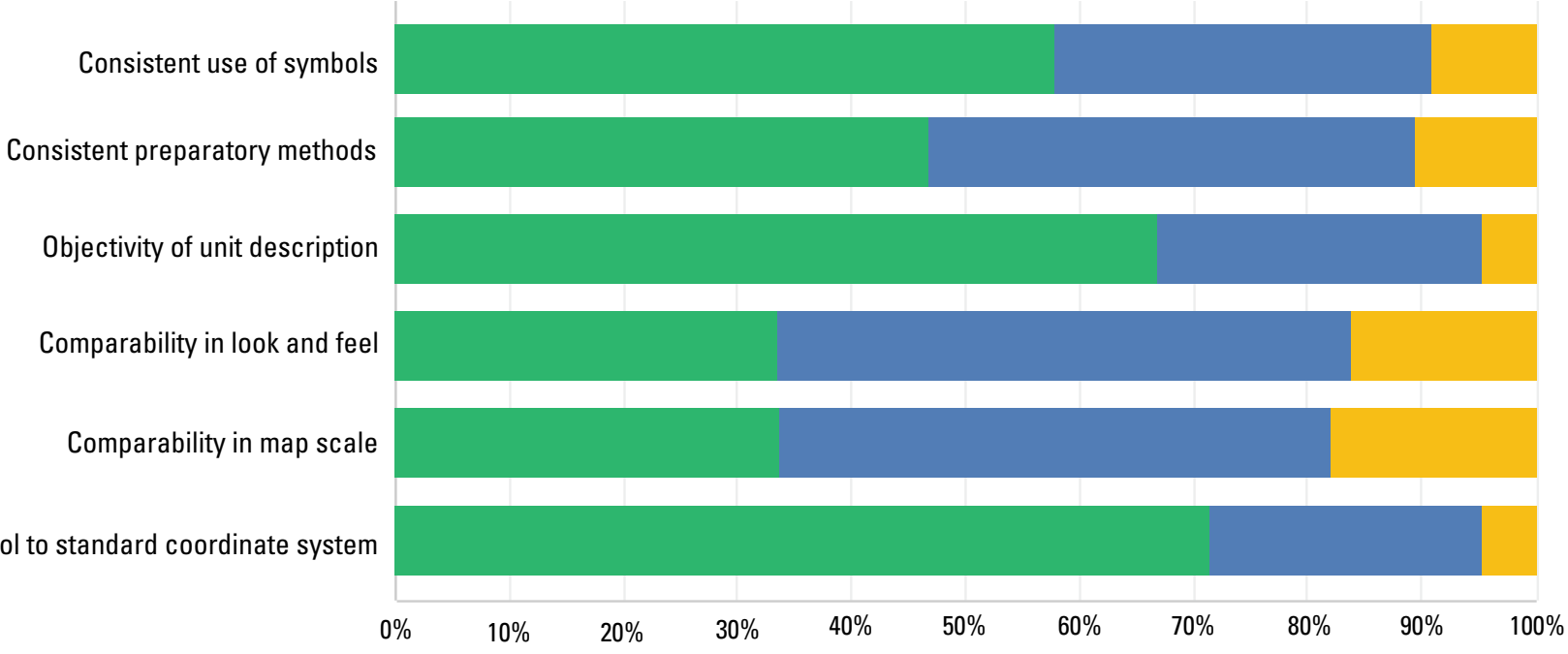

\section{EXPLANATION}

Very important

Somewhat important

Not important

\begin{tabular}{|c|c|c|c|c|}
\hline GEOSCIENCE MAP ELEMENTS & VERY IMPORTANT & SOMEWHAT IMPORTANT & NOT IMPORTANT & TOTAL \\
\hline Consistent use of symbols & $58 \%$ & $33 \%$ & $9 \%$ & \\
\hline Responses & 140 & 80 & 22 & 242 \\
\hline $\begin{array}{l}\text { Consistent preparatory methods } \\
\text { Responses }\end{array}$ & $\begin{array}{r}47 \% \\
112\end{array}$ & $\begin{array}{r}43 \% \\
102\end{array}$ & $\begin{array}{r}10 \% \\
25\end{array}$ & 239 \\
\hline $\begin{array}{l}\text { Objectivity of unit description } \\
\text { Responses }\end{array}$ & $\begin{array}{r}67 \% \\
161\end{array}$ & $\begin{array}{r}29 \% \\
69\end{array}$ & $\begin{array}{r}5 \% \\
11\end{array}$ & 241 \\
\hline $\begin{array}{l}\text { Comparability in look and feel } \\
\text { Responses }\end{array}$ & $\begin{array}{r}34 \% \\
80\end{array}$ & $\begin{array}{r}50 \% \\
120\end{array}$ & $\begin{array}{r}16 \% \\
38\end{array}$ & 238 \\
\hline $\begin{array}{l}\text { Comparability in map scale } \\
\text { Responses }\end{array}$ & $\begin{array}{r}34 \% \\
81\end{array}$ & $\begin{array}{r}48 \% \\
116\end{array}$ & $\begin{array}{c}18 \% \\
43\end{array}$ & 240 \\
\hline $\begin{array}{l}\text { Control to standard coordinate system } \\
\text { Responses }\end{array}$ & $\begin{array}{r}71 \% \\
173\end{array}$ & $\begin{array}{r}24 \% \\
58\end{array}$ & $\begin{array}{r}5 \% \\
11\end{array}$ & 242 \\
\hline
\end{tabular}

Figure 2.18. Importance of map elements to respondent work (question 19). 
020 Non-standardized geoscience maps that implement standard cartographic symbols sets and formats are useful than those that do not.

Answered: 242

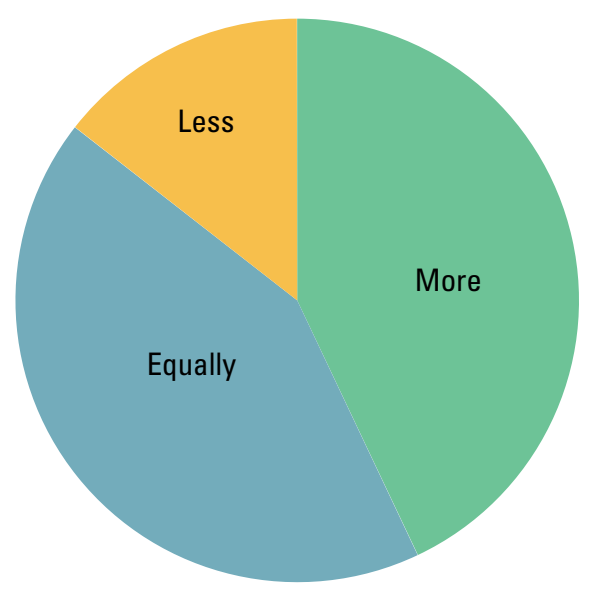

Skipped: 23

\begin{tabular}{llc} 
ANSWER CHOICES & RESPONSES & \\
More & $43 \%$ & 104 \\
\hline Equally & $43 \%$ & 103 \\
\hline Less & $14 \%$ & 35 \\
TOTAL & & 242
\end{tabular}

Figure 2.19. Respondent evaluation of standard cartographic symbols in non-standardized geoscience maps (question 20).

\section{Relevance of geoscience maps to establishing context for the scientific community?}

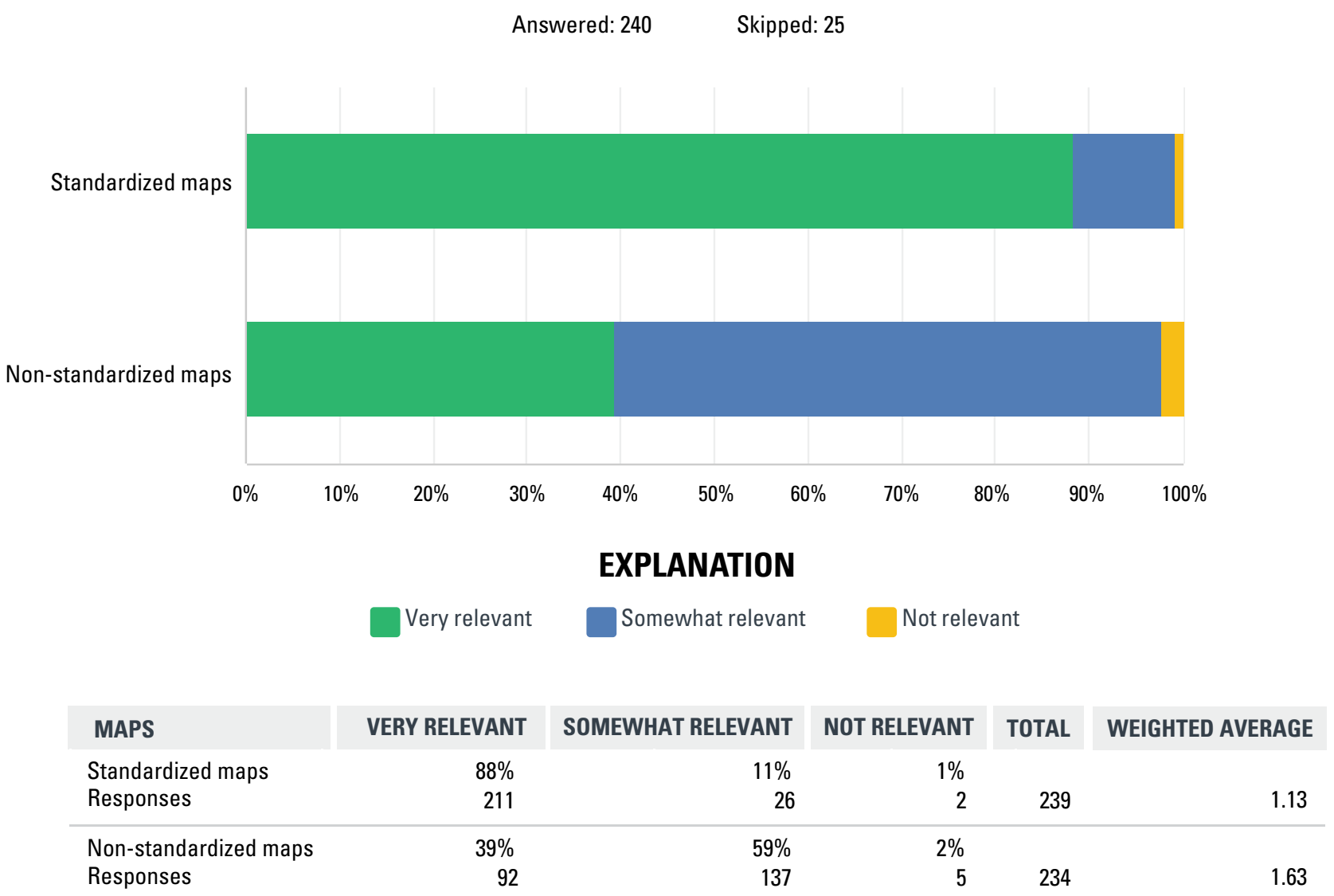

Figure 2.20. Relevance of geoscience maps to respondents in establishing context for scientific community (question 21). 


\section{You are knowledgeable of and can confidently apply standard geologic mapping processes.}

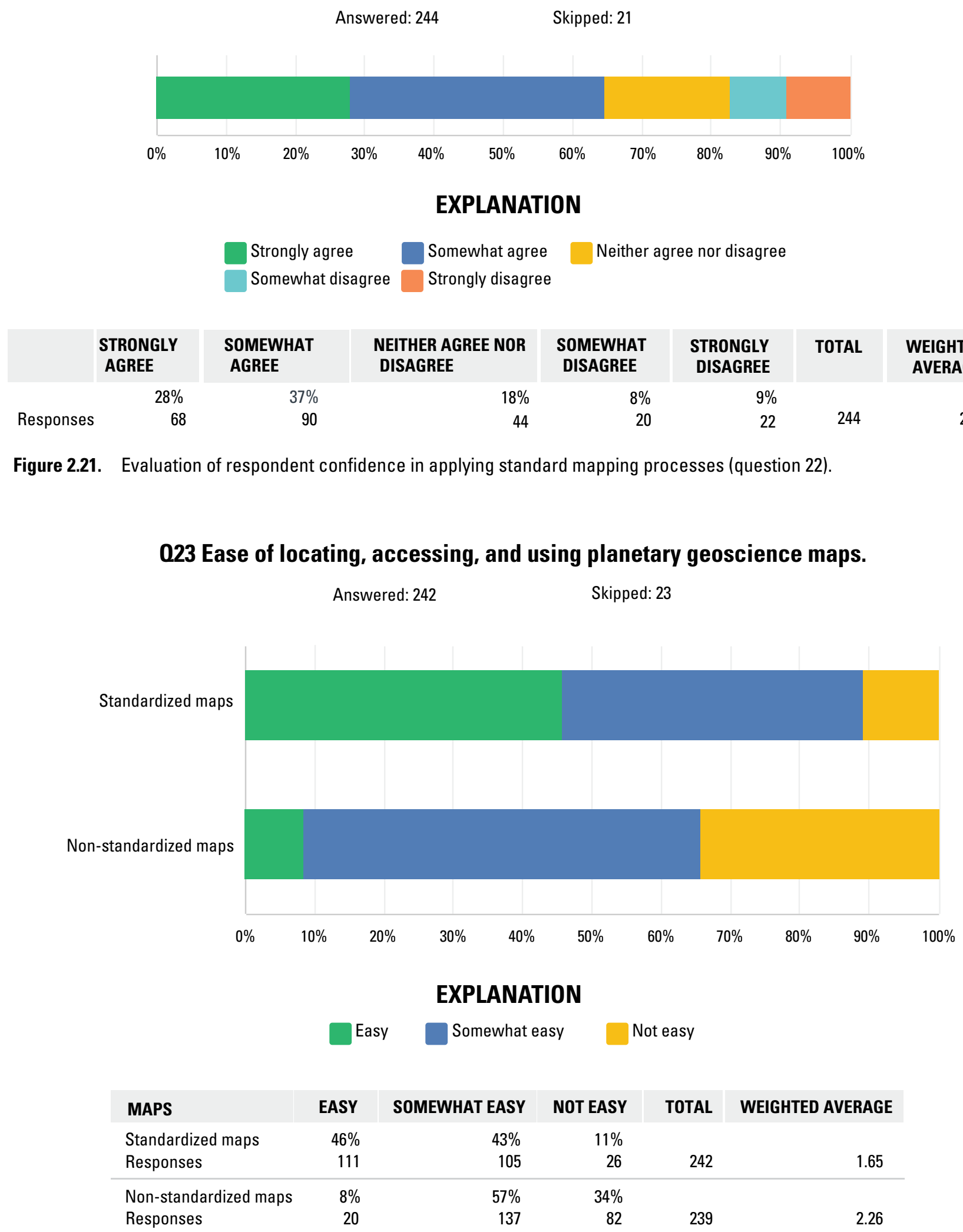

Figure 2.22. Respondent evaluation of geoscience map accessibility (question 23). 


\section{O24 Importance of the following geoscience map formats to your work?}

Answered: 241

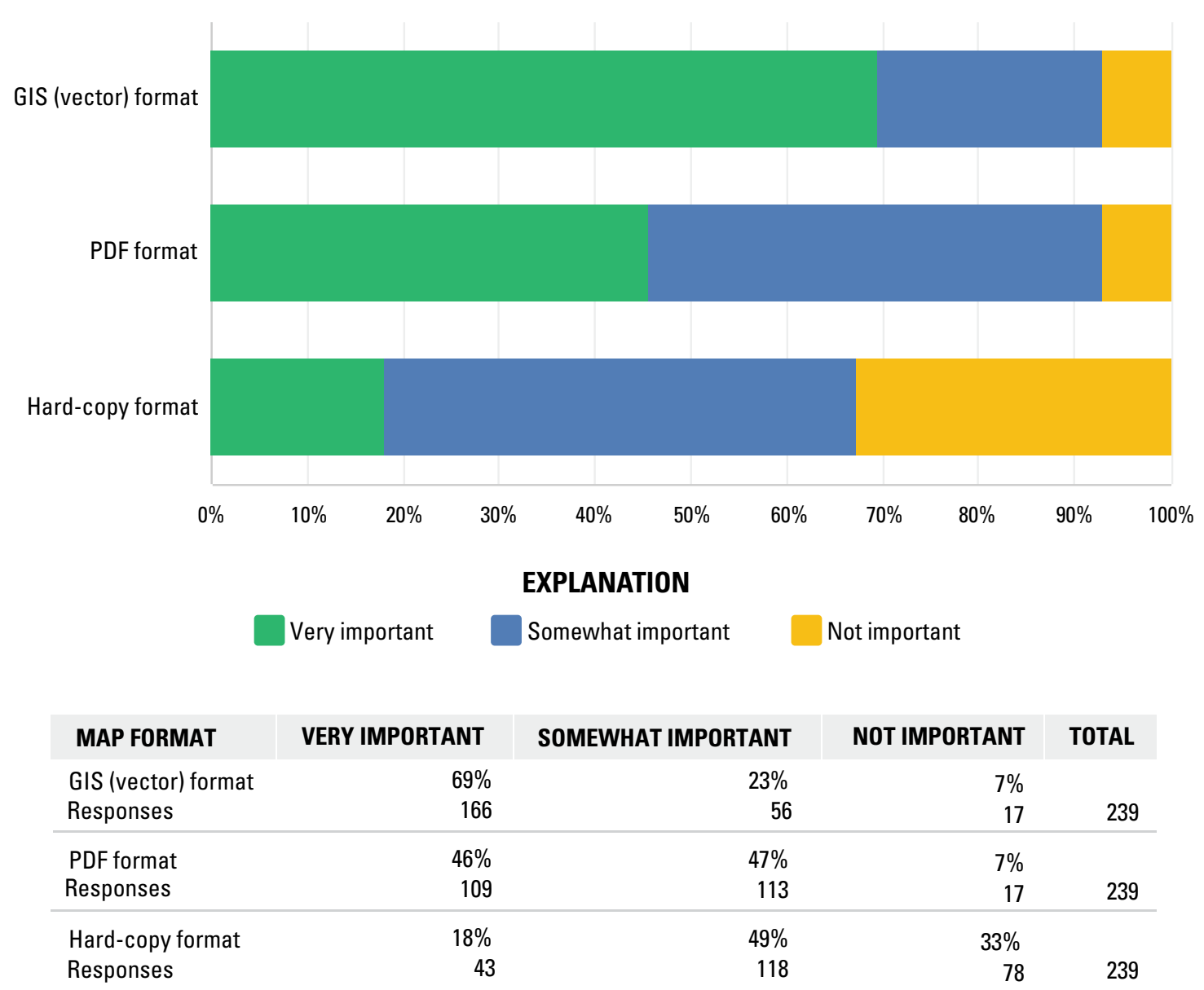

Figure 2.23. Importance of map formats to respondent work (question 24).

\section{You would find it useful to search for and access geoscience maps in one online location.}

$$
\text { Answered: } 241 \quad \text { Skipped: } 24
$$

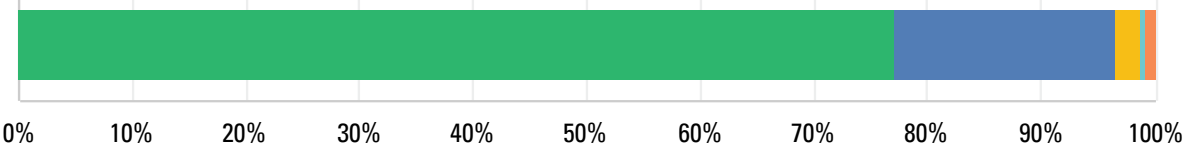

\section{EXPLANATION}

Strongly agree

Somewhat disagree
Somewhat agree

Strongly disagree

\begin{tabular}{|r|r|r|r|r|r|r|r|}
\hline $\begin{array}{c}\text { STRONGLY } \\
\text { AGREE }\end{array}$ & $\begin{array}{l}\text { SOMEWHAT } \\
\text { AGREE }\end{array}$ & $\begin{array}{c}\text { NEITHER AGREE NOR } \\
\text { DISAGREE }\end{array}$ & $\begin{array}{c}\text { SOMEWHAT } \\
\text { DISAGREE }\end{array}$ & $\begin{array}{c}\text { STRONGLY } \\
\text { DISAGREE }\end{array}$ & TOTAL & $\begin{array}{c}\text { WEIGHTED } \\
\text { AVERAGE }\end{array}$ \\
\hline Responses & $77 \%$ & $20 \%$ & $2 \%$ & $0 \%$ & $1 \%$ & \\
\end{tabular}

Figure 2.24. Respondent preference towards a single online repository of geoscience maps (question 25). 


\section{Surface science investigations fundamentally rely on spatial and temporal context established and refined by geoscience maps.}

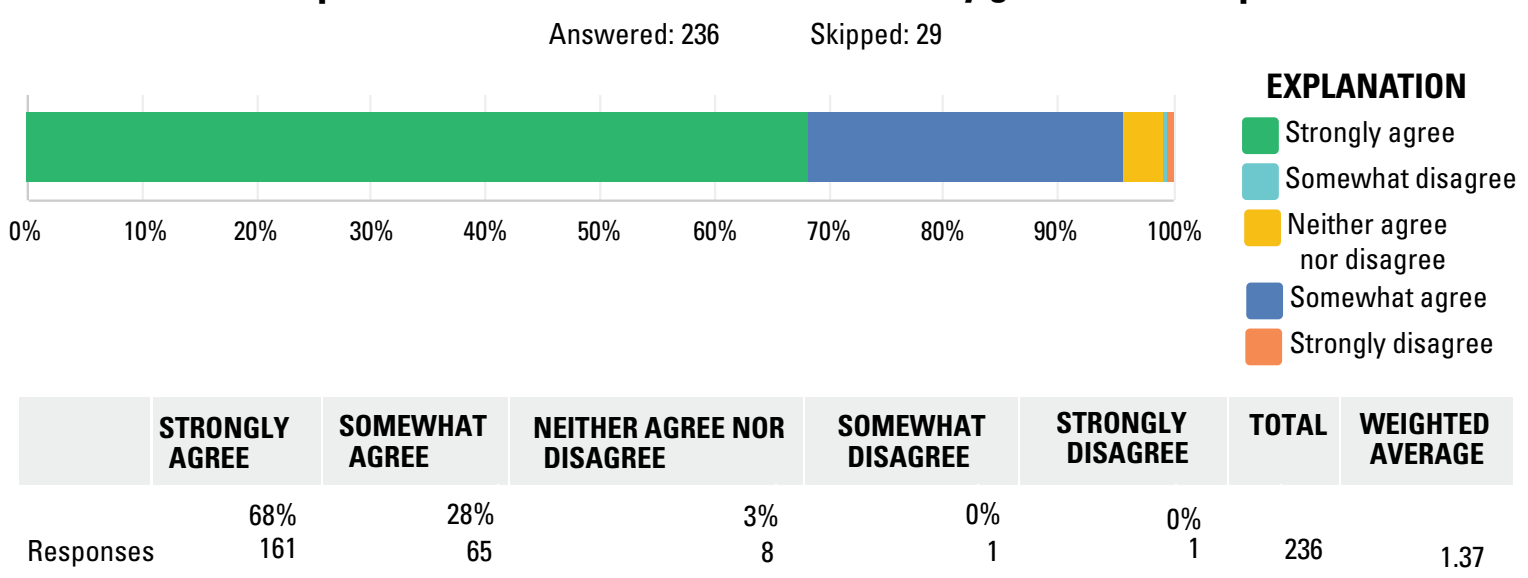

Figure 2.25. Respondent evaluation of geoscience maps as fundamental to surface science investigations (question 26).

027 Expedited production of standardized geoscience maps for areas of high interest and/or relevance would benefit both scientific investigations and potential future exploratory mission planning.

\section{EXPLANATION}

Answered: 237

Skipped: 28

\section{Strongly agree}

Somewhat disagree

Neither agree nor disagree

Somewhat agree

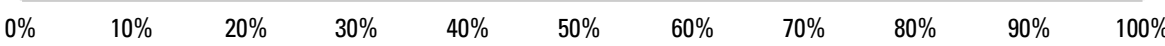

Strongly disagree

\begin{tabular}{|c|c|c|c|c|c|c|c|}
\hline & $\begin{array}{l}\text { STRONGLY } \\
\text { AGREE }\end{array}$ & $\begin{array}{l}\text { SOMEWHAT } \\
\text { AGREE }\end{array}$ & $\begin{array}{c}\text { NEITHER AGREE NOR } \\
\text { DISAGREE }\end{array}$ & $\begin{array}{c}\text { SOMEWHAT } \\
\text { DISAGREE }\end{array}$ & $\begin{array}{c}\text { STRONGLY } \\
\text { DISAGREE }\end{array}$ & $\begin{array}{c}\text { TOTAL } \\
\text { WISEIGHED } \\
\text { AVERAGE }\end{array}$ \\
\hline Responses & $63 \%$ & $27 \%$ & $8 \%$ & $0 \%$ & $1 \%$ & 237 & 1.49 \\
\hline
\end{tabular}

Figure 2.26. Respondent evaluation of expedited production of standardized geoscience maps (question 27).

028 Multi-year geologic mapping campaigns that focus on creating a series of maps for a particular body at a set map scale would be useful for the scientific community.

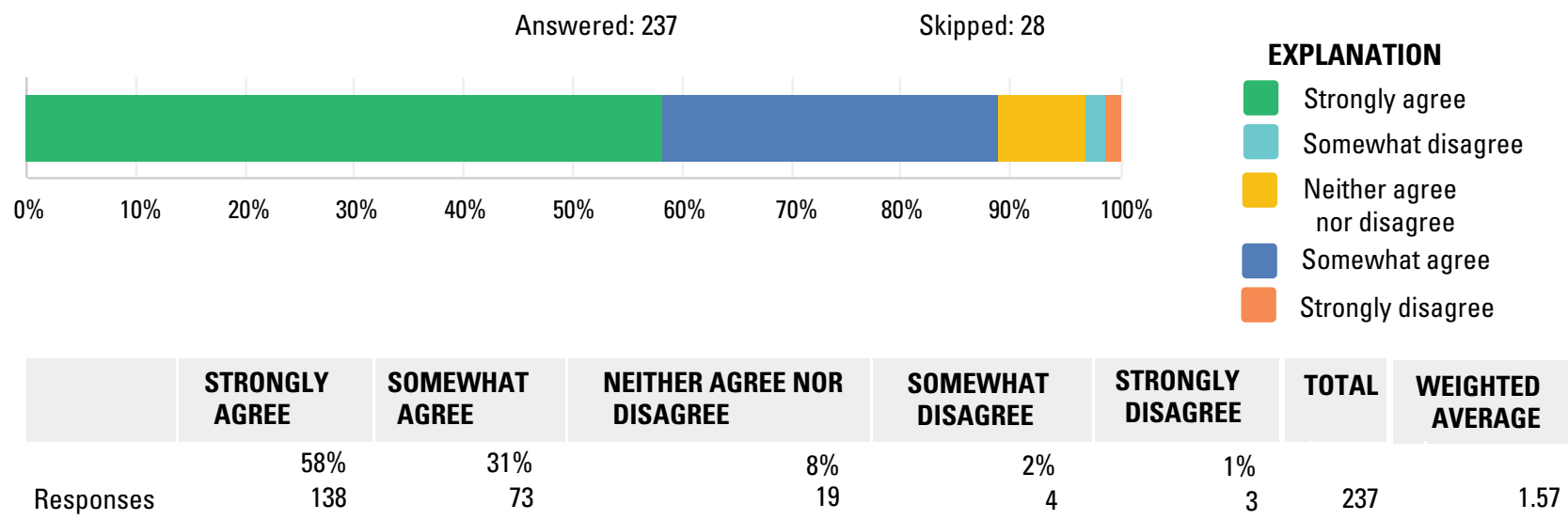

Figure 2.27. Respondent evaluation of multi-year mapping campaigns for particular planetary bodies and map scales (question 28). 


\section{Likelihood of using topical mapping guidance.}

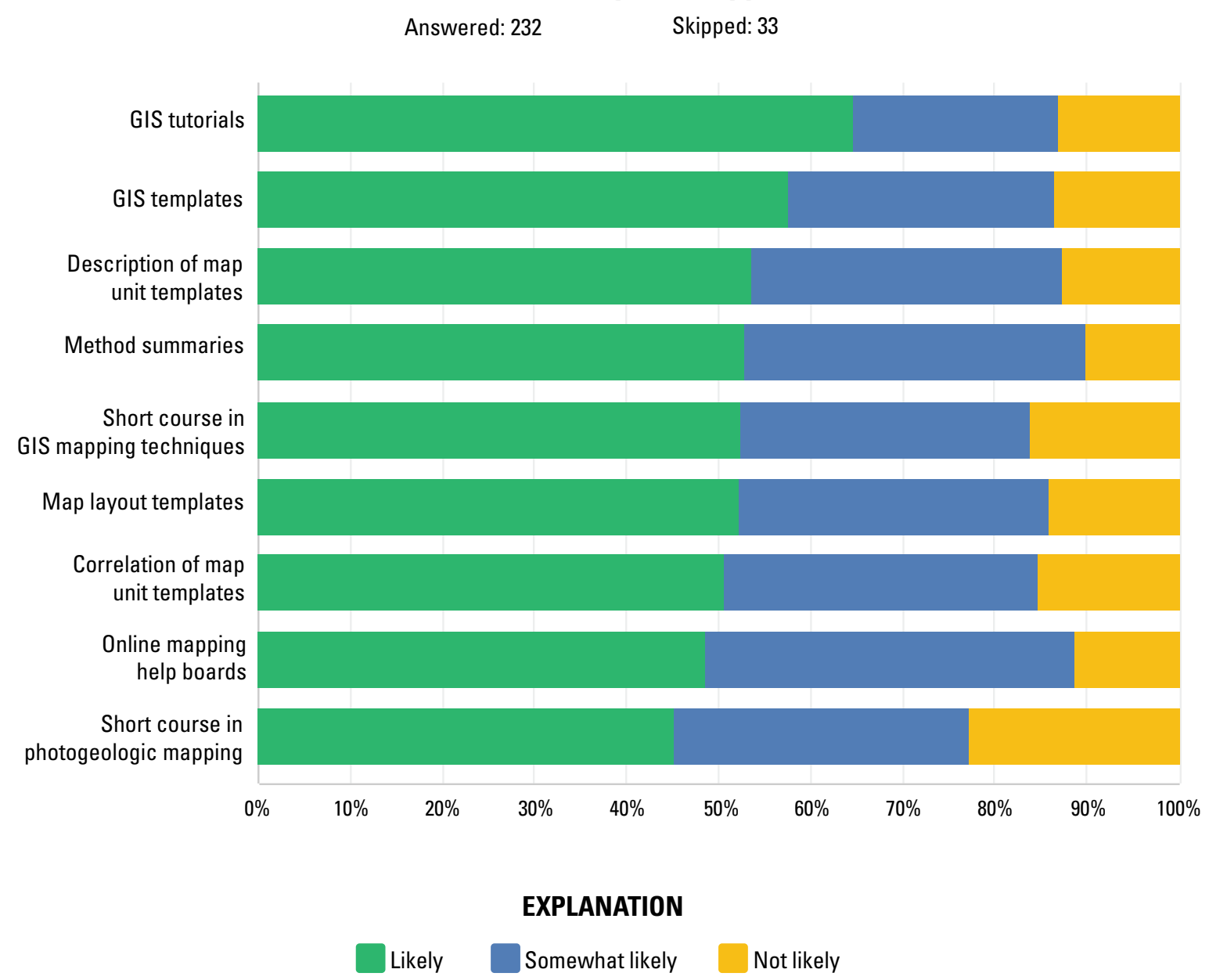

\begin{tabular}{|c|c|c|c|c|}
\hline USE OF TOPICAL MAP GUIDANCE & LIKELY & SOMEWHAT LIKELY & NOT LIKELY & TOTAL \\
\hline $\begin{array}{l}\text { GIS tutorials } \\
\text { Responses }\end{array}$ & $\begin{array}{r}65 \% \\
148\end{array}$ & $\begin{array}{r}22 \% \\
51\end{array}$ & $\begin{array}{r}13 \% \\
30\end{array}$ & 229 \\
\hline $\begin{array}{l}\text { GIS templates } \\
\text { Responses }\end{array}$ & $\begin{array}{r}58 \% \\
132\end{array}$ & $\begin{array}{r}29 \% \\
66\end{array}$ & $\begin{array}{r}14 \% \\
31\end{array}$ & 229 \\
\hline $\begin{array}{l}\text { Description of map unit templates } \\
\text { Responses }\end{array}$ & $\begin{array}{r}54 \% \\
123\end{array}$ & $\begin{array}{r}34 \% \\
77\end{array}$ & $\begin{array}{r}13 \% \\
29\end{array}$ & 229 \\
\hline $\begin{array}{l}\text { Method summaries } \\
\text { Responses }\end{array}$ & $\begin{array}{r}53 \% \\
121\end{array}$ & $\begin{array}{r}37 \% \\
85\end{array}$ & $\begin{array}{r}10 \% \\
23\end{array}$ & 229 \\
\hline $\begin{array}{l}\text { Short course in GIS mapping techniques } \\
\text { Responses }\end{array}$ & $\begin{array}{r}52 \% \\
120\end{array}$ & $\begin{array}{r}31 \% \\
72\end{array}$ & $\begin{array}{r}16 \% \\
37\end{array}$ & 229 \\
\hline $\begin{array}{l}\text { Map layout templates } \\
\text { Responses }\end{array}$ & $\begin{array}{r}52 \% \\
119\end{array}$ & $\begin{array}{r}34 \% \\
77\end{array}$ & $\begin{array}{r}14 \% \\
32 \\
\end{array}$ & 228 \\
\hline $\begin{array}{l}\text { Correlation of map unit templates } \\
\text { Responses }\end{array}$ & $\begin{array}{r}51 \% \\
116\end{array}$ & $\begin{array}{r}34 \% \\
78 \\
\end{array}$ & $\begin{array}{r}15 \% \\
35\end{array}$ & 229 \\
\hline $\begin{array}{l}\text { Online mapping help boards } \\
\text { Responses }\end{array}$ & $\begin{array}{r}49 \% \\
109\end{array}$ & $\begin{array}{r}40 \% \\
90\end{array}$ & $\begin{array}{r}11 \% \\
25\end{array}$ & 224 \\
\hline $\begin{array}{l}\text { Short course in photogeologic mapping } \\
\text { Responses }\end{array}$ & $\begin{array}{r}45 \% \\
104\end{array}$ & $\begin{array}{r}32 \% \\
74\end{array}$ & $\begin{array}{r}23 \% \\
52\end{array}$ & 230 \\
\hline
\end{tabular}

Figure 2.28. Likelihood of respondent use of topical mapping guidance (question 29). 
Menlo Park Publishing Service Center, California

Manuscript approved February 12, 2019

Edited by Phil Frederick

Layout by Kimber Petersen 


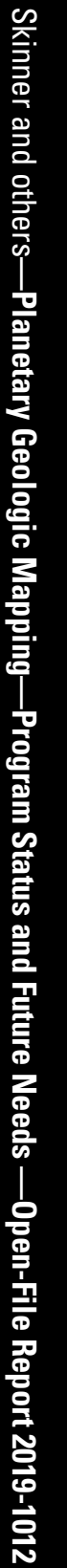

